\title{
Stereotypical Alterations in Cortical Patterning Are Associated with Maternal Illness-Induced Placental Dysfunction
}

\author{
Pamela A. Carpentier, Ursula Haditsch, Amy E. Braun, Andrea V. Cantu, Hyang Mi Moon, Robin 0. Price, \\ Matthew P. Anderson, Vidya Saravanapandian, Khadija Ismail, Moises Rivera, James M. Weimann, and \\ Theo D. Palmer \\ Stanford University, Institute for Stem Cell Biology and Regenerative Medicine, Stanford, California 94305-5454
}

We have previously shown in mice that cytokine-mediated damage to the placenta can temporarily limit the flow of nutrients and oxygen to the fetus. The placental vulnerability is pronounced before embryonic day 11, when even mild immune challenge results in fetal loss. As gestation progresses, the placenta becomes increasingly resilient to maternal inflammation, but there is a narrow window in gestation when the placenta is still vulnerable to immune challenge yet resistant enough to allow for fetal survival. This gestational window correlates with early cortical neurogenesis in the fetal brain. Here, we show that maternal illness during this period selectively alters the abundance and laminar positioning of neuronal subtypes influenced by the Tbr1, Satb2, and Ctip2/Fezf2 patterning axis. The disturbances also lead to a laminar imbalance in the proportions of projection neurons and interneurons in the adult and are sufficient to cause changes in social behavior and cognition. These data illustrate how the timing of an illness-related placental vulnerability causes developmental alterations in neuroanatomical systems and behaviors that are relevant to autism spectrum disorders.

\section{Introduction}

Maternal illness during early pregnancy has been associated with gestational complications and increased risk of neurodevelopmental disorders such as autism spectrum disorder (ASD) and schizophrenia (Brown et al., 2000; Beversdorf et al., 2005). Even mild illness such as the flu or noninfectious allergic and asthmatic reactions are clinically implicated as gestational risk factors in $\mathrm{ASD}$, and these associations are most significant when the immune events occur in first or second trimester (Croen et al., 2005). Prior studies have demonstrated that activation of the maternal innate immune system during pregnancy, even without viral or bacterial infection, is sufficient to cause diffuse neuroanatomical alterations and abnormalities in social behavior, complex learning tasks, and sensorimotor gating (Shi et al., 2003; Zucker-

Received Sept. 28, 2012; revised Aug. 13, 2013; accepted Sept. 9, 2013.

Author contributions: J.M.W. and T.D.P. designed research; P.A.C., U.H., A.E.B., A.V.C., H.M.M., R.O.P., M.P.A., V.S., K.I, M.R., J.M.W., and T.D.P. performed research; P.A.C., U.H., A.E.B., A.V.C., H.M.M., M.P.A., J.M.W., and T.D.P. analyzed data; P.A.C., U.H., and T.D.P. wrote the paper.

This work was supported by grants to T.D.P. from the March of Dimes, Autism Speaks, Simons Foundation, and National Institutes of Health (NIH)/National Institute of Mental Health (1R01MH096815) and grants to P.A.C. from the NIH (National Institute of Neurological Disorders and Stroke, 5F32NS60427) and the Lucile Packard Foundation. We thank Elizabeth Alcamo and Susan McConnell for experimental advice and helpful comments. We also thank the Stanford Behavioral and Functional Neuroscience Service Center for technical assistance with PPI and Social Interaction paradigms.

Correspondence should be addressed to Theo D. Palmer, Stanford University, Institute for Stem Cell Biology and Regenerative Medicine, 265 Campus Drive, Room 1141, Stanford, CA 94305-5454. E-mail: tpalmer@stanford.edu.

M. Anderson's present address: Interdepartmental Program in Neuroscience, University of California, Los Angeles, 1506D Gonda Center/695 Young Drive South, Los Angeles, CA 90095-1761.

K. Ismail's present address: 1945 Eastchester Road, Bronx, NY 10461.

R.0. Price's present address: Covidien-GI Solutions, 540 0akmead Parkway, Sunnyvale, CA 94085.

DOI:10.1523/JNEUROSCI.4654-12.2013

Copyright $\odot 2013$ the authors $\quad 0270-6474 / 13 / 3316874-15 \$ 15.00 / 0$ man et al., 2003; Golan et al., 2005; Meyer et al., 2006, 2008). We have recently shown that maternal cytokine-induced disruption of placental function is a contributing factor in this process (Carpentier et al., 2011).

Before mid-gestation in mice, the placenta is so sensitive to lipopolysaccharide (LPS)-induced maternal proinflammatory cytokines that even low doses of LPS can trigger TNF- $\alpha$ dependent spontaneous termination (Carpentier et al., 2011). At approximately embryonic day 13 (E13), the placenta undergoes an extensive developmental switch in gene expression patterns (Knox and Baker, 2007, 2008), and, by E14.5, the placenta becomes resistant to cytokine challenge (Carpentier et al., 2011). The timing of this transition from vulnerable to resilient creates a narrow window of gestation when the mouse placenta has become resilient enough for an immunologically challenged pregnancy to proceed to term, yet still vulnerable to low levels of cytokines. It also time locks the potential impact of a placental vulnerability to periods of active neurogenesis in the developing forebrain. Here we examine cortical neurogenesis and resulting adult anatomy in mice challenged with LPS to better understand the range of neurodevelopmental processes that may be influenced by maternal infections during this window of vulnerability.

We have found that mild immune activation at E12.5 is accompanied by placental damage, transient fetal hypoxia, reduced neural progenitor cell proliferation, and premature cell cycle exit in the developing cortex. These changes ultimately result in a decrease in the number of E12.5-born cells in deep layers of the cortex and a proportional increase in the number of E12.5-born cells in the superficial cortical layers in the adult mice. The abundance and laminar positioning of projection neuron and in- 
terneurons are also affected, with the most notable impact on three pyramidal neuron subtypes whose cerebral or subcerebral projection patterns are specified by Satb2 and Tbr1, or Ctip2/ Fezf2-mediated cascades, respectively. The combined disturbances in neurodevelopment are sufficient to alter social behavior and cognitive processing in adult offspring. Together, these data suggest that mild illness during the period of placental vulnerability is sufficient to cause a patterned imbalance in projection neuron identity, laminar distribution, and excitatory/inhibitory neuron ratios present in the adult.

\section{Materials and Methods}

Animals. All animal studies were performed in accordance with National Institutes of Health guidelines for the humane use of animals, and all procedures were reviewed and approved by the Stanford Institutional Animal Care and Use Committee. C57BL/6J mice purchased from The Jackson Laboratory were used for all studies.

Timed pregnancies and treatments. To generate timed pregnancies, pairs of females were housed with a single male overnight. Mice were separated the next day, and noon on that day is termed E0.5 for these studies. At E12.5, pregnant mice were injected intraperitoneally with saline or LPS from Escherichia coli (Sigma-Aldrich) at $60 \mu \mathrm{g} / \mathrm{kg}$ body weight prepared at a concentration of $12 \mu \mathrm{g} / \mathrm{ml}$ in saline. All chemicals were purchased from Sigma-Aldrich except where otherwise noted. For all animals tested postnatally, pups were fostered at birth to wild-type naive mothers with litters between 1 and $5 \mathrm{~d}$ old (which were removed). Pups were weaned at 3 weeks of age and group housed at $2-5$ mice per cage in standard microisolator cages with a $12 \mathrm{~h}$ light/dark cycle. Animals being analyzed for hypoxia received an intraperitoneal injection of pimonidazole (100 mg/kg; Hypoxyprobe-1, Hypoxyprobe) $15 \mathrm{~min}$ before saline or LPS. To assess fetal neural precursor proliferative activity, some pregnant mice received one injection of Iododeoxy uridine (IdU, 100 $\mathrm{mg} / \mathrm{kg}, 5 \mathrm{mg} / \mathrm{ml}$ ) or chlorodeoxyuridine (CldU; $100 \mathrm{mg} / \mathrm{kg}, 10 \mathrm{mg} / \mathrm{ml}$ ) at E12.5, E13.5, or E15.5.

Immunofluorescent staining and antibodies. Tissue was fixed with $4 \%$ paraformaldehyde and equilibrated in $30 \%$ sucrose. Adult brains were harvested and sectioned on a freezing sledge microtome. Whole fetal heads and postnatal heads were harvested and sectioned on a Microm HM505E cryostat (Fisher Scientific). Free-floating brain tissue sections or cryostat sections mounted on glass slides were rinsed twice with Trisbuffered saline (TBS) and DNA was denatured with $2 \mathrm{~N} \mathrm{HCl}$ for $20 \mathrm{~min}$ at $37^{\circ} \mathrm{C}$. Samples were rinsed twice with TBS and blocked at room temperature in TBS plus $0.3 \%$ Triton X-100 and 3-10\% normal donkey serum (NDS; Jackson ImmunoResearch) for $2 \mathrm{~h}$ at room temperature. Tissue sections were then incubated with primary antibody in staining buffer (TBS plus $0.3 \%$ Triton X-100 and 1\% NDS; tissue sections) overnight at $4^{\circ} \mathrm{C}$. The antibodies in this study were as follows: mouse anti-pimonidazole at 1:50 (Hypoxyprobe), rabbit anti-phospho-Histone H3 (1:400; Cell Signaling Technology), mouse anti-bromodeoxyuridine (BrdU; 1:200; BD Biosciences, cross-reacts with IdU), rat anti-BrdU (1:500; Accurate Chemical and Scientific; cross-reacts with CldU), rabbit anti-Ki67 (1:200; Novocastra, Leica Microsystems), goat anti-doublecortin (1:500; Santa Cruz Biotechnology), rabbit anti-Ctip2 (1:200; Novus Biologicals), mouse antiSatb2 (1:100; Abcam), rabbit anti-Tbr1 (1:100; Abcam), goat anti-Cuxl (1: 100; Santa Cruz Biotechnology), anti-GABA (1:500; Sigma-Aldrich), mouse anti-parvalbumin (1:5000; Millipore Bioscience Research Reagents), rabbit anti-calretinin (1:500; Millipore), mouse anti-calbindin (1:500; Swant, Swiss antibodies), and goat anti-reelin at (1:200; R\&D Systems). After washing three times with TBS, tissue was incubated with donkey secondary antibodies conjugated to FITC, Cy3, or Cy5 (1:500; Jackson ImmunoResearch) for $4 \mathrm{~h}$ at room temperature or overnight at $4^{\circ} \mathrm{C}$. Tissue was washed twice in TBS and incubated with 4',6-diamidino-2-phenylindole (DAPI) at 0.1 $\mu \mathrm{g} / \mathrm{ml}$ for $10 \mathrm{~min}$ at room temperature. Tissue was then fixed with $4 \%$ paraformaldehyde for $10 \mathrm{~min}$ at room temperature, washed, and coverslips were mounted using polyvinyl alcohol and 1,4 diazabicyclo[2.2.2] octane in glycerine (PVA-DABCO).

Confocal microscopy, image analysis, and cell counts. Four-color confocal microscopy was performed on a Zeiss 700 confocal microscope with gain and offset adjusted on the brightest and dimmest sections of an entire staining set. This avoided data clipping with undersaturated and oversaturated pixels and ensured that images could be collected from all animals in a given experiment without changing settings. Images were collected using the $40 \mathrm{X}$ oil objective with automated tiling to generate a high-resolution image montage that spanned the entire thickness of the cortex. The images were then evaluated by an experimenter blind to treatment, and postcollection processing was applied using automated scripts developed in Photoshop CS4 or CS5 (Adobe). Adjustments to optimize signal-to-noise and enhance threshold-based object counting in ImageJ were determined empirically. The adjustments were then recorded and saved as a sequence of "actions" in Photoshop and then applied to all images in a given dataset using the "automate" function in Photoshop.

Postprocessed confocal images were then scored in ImageJ/Fiji by applying the color threshold tool and "analyze particles" tool. Object area and circularity thresholds for each stain or object type were empirically determined and the accuracy of the automated counts verified by manually scoring a subset of images. Iterative adjustments to image processing, color threshold, and "analyze particles" variables were made until automated counts were within $3 \%$ of manually scored samples. Object area, average pixel intensity, and centroid $X$ and $Y$ coordinates were output to Excel. $X$ and $Y$ coordinates defining the pial surface and dorsal surface of the corpus callosum (CC) were also recorded for each image. Ventricular surface was used instead of CC in fetal samples. The laminar position of a given object was then calculated as a fraction of the distance between pia and CC (or ventricular wall).

For cell cycle analysis in the fetal cortex, $20 \mu \mathrm{m}$ cryostat sections were stained for IdU, CldU, Ki67, and DAPI. Three or more sections were scored for each fetus, and the number and relative position for DAPI nuclei that were also positive for IdU, CldU, and/or Ki67 were scored (single- double-, or triple-labeled nuclei).

For adult tissue scoring, $40 \mu \mathrm{m}$ coronal sections were serially collected throughout the entire anterior-posterior $(\mathrm{A}-\mathrm{P})$ axis of the brain. Every 24th section was stained for each marker ( $960 \mu \mathrm{m}$ sampling interval). Staining for a given marker was performed at the same time on all sections to be scored to ensure that each section received identical treatment and that technical variation in staining intensity was minimized across animals. For adult cortical projection neuron and interneuron counts, cells were scored in three coronal sections separated from each other by 960 $\mu \mathrm{m}(\sim 1.8 \mathrm{~mm}$ of dorsal medial cortex sampled). The anterior section in the series was located at the head of the dorsal lateral ventricles and the third section located at the rostral tip of the hippocampal formation.

Image $J$ or the Fiji implementation of ImageJ was used to score the number of positive cells and their $X$ and $Y$ coordinates relative to pia and the CC. For each cell type, the relative laminar position was determined as a fraction of the distance between the pia and CC and data were grouped into 10 "bins" or lamina of equal thickness. Total cell density was scored as the average total number of cells scored per $\mathrm{mm}^{2}$ of tissue in all lamina. Cortical thickness was calculated as the linear distance from pia to the dorsal margin of the callosal white matter measured $\sim 1 \mathrm{~mm}$ lateral to midline. To more readily illustrate treatment effects on the net change in cell density for each laminar bin, an LPS-induced change in laminar cell density was calculated by subtracting the saline control cell density from LPS cell density for each bin.

Retrograde tracing. $0.5 \mathrm{~mm}^{2}$ squares of Gelfoam absorbable gelatin sponge (Pfizer) were soaked in a solution containing Alexa Fluor 594labeled cholera toxin $\beta$ (CTB, $1 \mathrm{mg} / \mathrm{ml}$ in PBS; Invitrogen) and surgically positioned unilaterally at four equally spaced A-P locations within the sensorimotor and frontal cortex of postnatal day 6 (P6) pups. Three days later (P9) pups were perfused with $4 \%$ paraformaldehyde. Cryostat sections $(18 \mu \mathrm{m})$ were collected and counterstained for Satb2 as above, and cortical neurons were examined by confocal microscopy for evidence of retrograde labeling in the hemisphere contralateral to the Gelfoam implants. Nine sections per mouse evenly distributed throughout the retrograde-labeled cortex were scored for the number of CTB tracerfilled neurons that colabeled for Satb2.

Open field exploration. Individual mice were placed in a black square open box $(70 \times 70 \times 50 \mathrm{~cm})$ and were allowed to explore the novel open 
field for $5 \mathrm{~min}$. A video tracking system (ViewPoint) automatically recorded the location, the path, and the speed of the mouse in the arena.

Social interaction. Sociability and social memory were tested in an adaptation of the three-chamber test (Crawley, 2007). Briefly, the threechamber apparatus contains three equal sized chambers: an empty middle chamber and chambers on either end that contain an inverted wire pencil cup, which is used to hold a stimulus mouse. The test has three phases. First, mice were habituated in their home cage to the experimental room for $1 \mathrm{~h}$. The test mouse was then placed in the testing apparatus and allowed to explore the chambers, with the inverted but empty pencil cups, for $10 \mathrm{~min}$. The subject was then removed and a novel mouse placed under one of the pencil cups. The location of the novel mouse was randomized to left and right chambers. The test subject was then placed in the middle chamber and its activity recorded for $10 \mathrm{~min}$. For the social memory test, the previously used stimulus mouse (familiar mouse) was placed in the chamber opposite to its original location and a new mouse (novel mouse) was placed in the other chamber. The test mouse was again placed in the center chamber and the amount of time spent in each chamber and the number of chamber entries were automatically recorded. An experimenter blind to mouse treatment scored the videos to determine the amount time to initiate contact with the stimulus mouse and the total amount of time spent sniffing empty pencil cups or the stimulus mice using JWatcher software (Bozdagi et al., 2010; Silverman et al. 2013).

Olfactory function. After testing in the social interaction test, mice were tested for olfactory function using a buried food test (Yang and Crawley, 2009). For $2 \mathrm{~d}$ preceding the test, mice were given food treats (Froot Loops) in their cages to habituate them to this food. The evening before the test, all food was removed from the cages. The next morning, mice were allowed to habituate to the testing room for $1 \mathrm{~h}$ in their home cage. They were then habituated to a new testing cage with $3 \mathrm{~cm}$ of bedding for $5 \mathrm{~min}$. Mice were moved to a holding cage while the food was buried under the bedding in the testing cage. Mice were returned to the testing cage and the amount of time required to find the buried food was recorded by an experimenter blind to treatment group.

Prepulse inhibition. Animals were habituated to the acoustic startle chamber (Med Associates) using a background of $65 \mathrm{~dB}$ white noise. Startle amplitude and prepulse inhibition (PPI) of the startle response were documented using a randomized series of prepulse-pulse pairs. Platform displacement was recorded for each animal during a $100 \mathrm{~ms}$ null period followed by a $20 \mathrm{~ms}$ white noise prepulse of $0 \mathrm{~dB}, 68 \mathrm{~dB}, 70$ $\mathrm{dB}, 75 \mathrm{~dB}$, or $80 \mathrm{~dB}$. The prepulse was followed $100 \mathrm{~ms}$ later by a $40 \mathrm{~ms}$ white noise acoustic startle pulse of $120 \mathrm{~dB}$. Startle response was recorded during the $140 \mathrm{~ms}$ after the startle pulse and peak platform displacement was used to calculate startle amplitude and prepulse inhibition. Each prepulse-pulse pair was tested in a randomized sequence for a total of 12 replicates for each tone pair. Intertrial intervals (ITIs) are randomly varied between 10 and $20 \mathrm{~s}$. Percentage PPI was calculated for each animal as follows: ((average startle amplitude with no prepulse - average amplitude with the indicated prepulse)/(average startle amplitude with no prepulse) $) \times 100$.

Delayed match-to-place task. The water maze consisted of a circular black tank ( $170 \mathrm{~cm}$ diameter, $43 \mathrm{~cm}$ deep) filled with water $\left(23-25^{\circ} \mathrm{C}\right)$ containing nontoxic tempera paint (Rich Art Color) to obscure the submerged platform ( $13 \mathrm{~cm}$ diameter, $29 \mathrm{~cm}$ height). Training in the delayed match-to-place (DMP) task was performed as previously described (Haditsch et al., 2009). The platform was moved to a new location each day, but, within each day, the platform location remained constant. There were 13 possible platform locations, each used only once. At the start of each trial, the mouse was gently placed into the water with its head facing the wall of the pool. The start location varied semirandomly between trials (three different starting locations spaced evenly around the pool). The DMP training consisted of six training trials per day with 10 to 15 min ITIs on days $1-12$ and $1 \mathrm{~h}$ ITI on day 13 . If a mouse did not find the platform within a $60 \mathrm{~s}$ trial, it was placed onto the platform by the experimenter, stayed there for $15 \mathrm{~s}$, and then removed to a warmed home cage. Swim speed, path length, and location data were collected using a video tracking system (Videotrack Automated Behavioral Analysis System; ViewPoint Life Sciences). Visible platform testing occurred after the
DMP task was complete. During the visible platform training, the submerged platform location was indicated by a flag rising above the water line and visible from all areas within the pool. The experimenter was blind to treatment for all behavioral tests.

Statistics. Statistical analysis was performed using Statistica software (StatSoft) or GraphPad Prism (GraphPad Software). For comparisons between two means, two-tailed Student's $t$ test was used. For comparisons in assays that varied by two variables, two-way ANOVA was performed with Bonferroni post hoc tests. For analysis of cell location and density in cortical tissue sections, a Student's $t$ test analysis of all laminar bins combined was used to determine whether there was a statistical change in overall density for a given marker. Data were also divided into inner and outer laminar bins and two-way ANOVA was performed separately for lamina populated by cells normally born during the challenge (bins 6-10) versus lamina populated by cells generated after the challenge has resolved (bins 1-5). For social behavior tasks, analysis of time spent in the chambers during habituation and time spent sniffing in the sociability and social memory tasks for all animals were analyzed by two-way ANOVA with repeated measures and treatment as the betweensubject factor and chamber, stimulus, or time as the within-subject subject factor. In repeated measures comparisons conducted for the DMP task, dependent variables were analyzed using ANOVA with treatment as the between-subject factor, and session as the within-subject factor with the Newman-Keuls post hoc tests. Means \pm SEM are presented in all figures. For startle responses and PPI, data were analyzed by two-way ANOVA with repeated measures with treatment as the between-subjects factor and startle event or prepulse level as the within-subjects factor. For open field testing, dependent variables were analyzed using ANOVA with treatment as the between-subject factor and region as the within-subjects factor.

\section{Results}

Mild fetal hypoxia and defects in neural progenitor proliferation accompany cytokine-induced placental pathology

We have previously reported that the fetus experiences hypoxia transiently after an LPS-induced mild maternal immune response at E12.5 (Carpentier et al., 2011). To more comprehensively evaluate the levels of hypoxia in different regions of the fetal brain, pimonidazole was injected 15 min before saline or LPS injection and fetal brains were collected $2 \mathrm{~h}$ after LPS injection. Pimonidazole staining was evaluated by immunofluorescence in the cortex, thalamus, median ganglionic eminence (MGE), and lateral ganglionic eminence (LGE) (Fig. $1 A$ ). Immune challenge in the mother resulted in a significant increase in fraction of fetal brain tissue area that was pimonidazole-positive within the cortex, thalamus, and LGE (Fig. $1 B$ ). Of these regions, the cortex displayed the largest increase in staining.

\section{Hypoxia is accompanied by alterations in neural progenitor proliferation and cell cycle exit}

We have shown that mitotic activity in the developing cortex is reduced during the inflammatory challenge and accompanying hypoxia (Carpentier et al., 2011). To more fully document alterations in neural progenitor activity that accompany LPS-induced placental damage, mice were injected with saline or LPS at E12.5. IdU was injected $2 \mathrm{~h}$ later to label cells in S-phase. CldU was injected $22 \mathrm{~h}$ later at E13.5 to labels cells in S-phase and fetal brains were harvested $2 \mathrm{~h}$ later ( $24 \mathrm{~h}$ after LPS or saline injection). Brains were stained for DAPI (nuclei), IdU, CldU, and Ki67, a marker of cells that are competent to enter the cell cycle (Fig. 1C). As expected from our prior data, the abundance of IdU-positive cells that were in S-phase $2 \mathrm{~h}$ after LPS or saline injection was reduced in LPS-challenged mice (Fig. 1D). Twenty-four hours later, the mitotic index measured by CldU-positive cells re- 

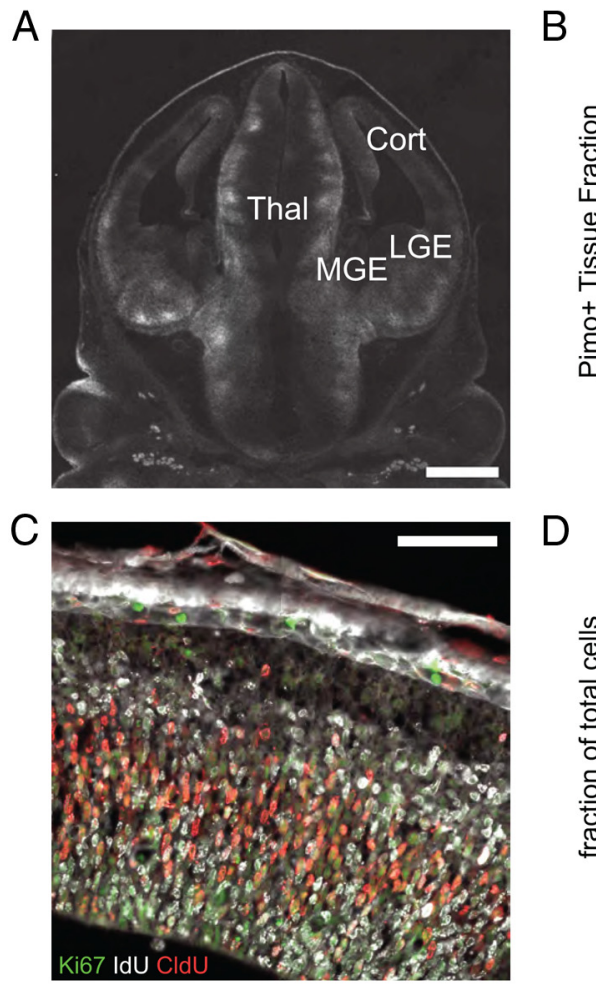

\section{D}
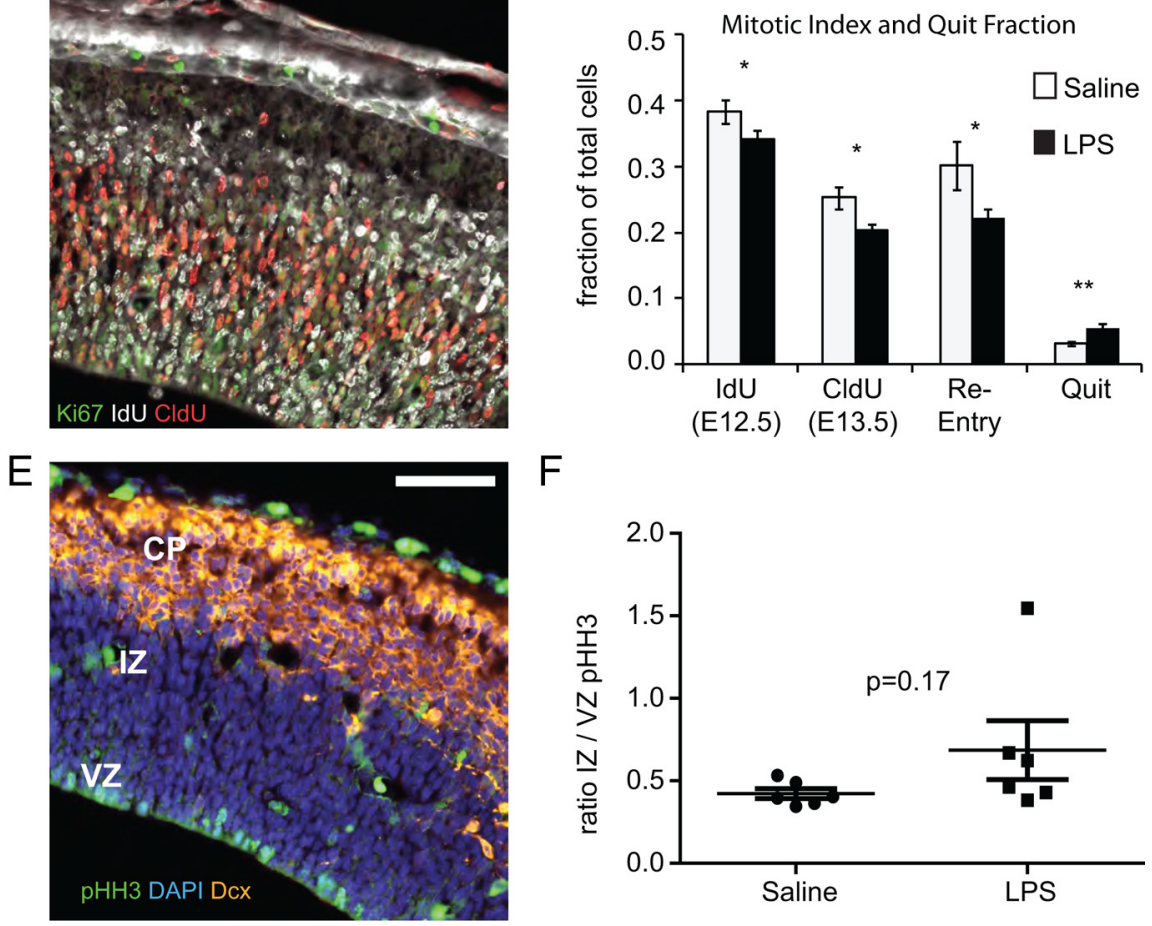

F

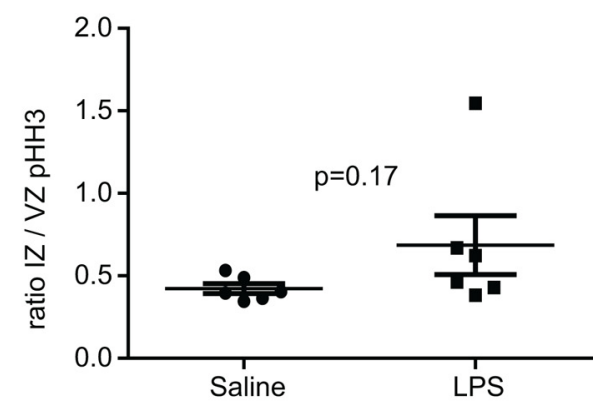

Figure 1. Hypoxia and alterations in neural progenitor cell cycle. $\boldsymbol{A}$, The extent of hypoxia in fetal brain tissue was estimated by treating pregnant mice with pimonidazole $15 \mathrm{~min}$ before injecting saline or LPS $(60 \mu \mathrm{g} / \mathrm{kg})$ at E12.5. Two hours after saline or LPS injection, fetuses were harvested and coronal brain sections were processed and stained for pimonidazole adducts (white). Scale bar, $100 \mu \mathrm{m}$. B, Pimonidazole staining was quantified as the proportion of tissue area showing positive staining for each brain area. Pimonidazole staining was most pronounced in the cortex following LPS administration $\left({ }^{*} p<0.05,{ }^{* * *} p<0.0001\right.$, two-tailed Student's $t$ test, $n=9-12$ saline and 12-15 LPS brains from 3-5 pregnancies per group). C, Perturbations in cell cycle and quit fraction were evaluated in coronal sections of fetal cortex at E13.5. Pregnant mice received an injection of IdU (100 mg/kg) $2 \mathrm{~h}$ after saline or LPS and CldU (100 mg/kg) $20 \mathrm{~h}$ after that. Two hours after CldU, fetal brains were harvested, fixed, sectioned, and stained for IdU, CldU, and Ki67. Nuclei were counterstained with DAPI. Scale bar, $50 \mu \mathrm{m}$. D, The IdU index and CldU index were calculated as the fraction of DAPI-positive nuclei staining with the marker. The re-entry fraction is the fraction of IdU-positive cells, which are also CldU-positive, and the quit fraction is the fraction of IdU-positive cells, which are Ki67-negative. LPS-challenged mice demonstrate a decreased IdU and CldU index ( ${ }^{*} p=0.047$ and 0.031 , respectively, two-tailed Student's $t$ test), decreased re-entry fraction $\left({ }^{*} p=0.049\right.$, two-tailed Student'st test), and increased quit fraction $\left({ }^{* *} p=0.0014\right.$, two tailed Student's $t$ test) compared with saline $(n=10$ per group from 2 separate experiments). $\boldsymbol{E}, \boldsymbol{F}$, Fetal brains were harvested at E13.5, $24 \mathrm{~h}$ after saline or LPS challenge, and stained for pHH3, DCx, and DAPI. pHH3-positive cells in the VZ or IZ were counted and the ratio VZ/IZ was determined. Variance was greater for LPS-challenged fetuses but the mean was not significantly different between groups ( $p=0.17$, two-tailed Student's t test, $n=7$ LPS, $n=8$ saline from at least 2 pregnancies for each group). Scale bar, $50 \mu \mathrm{m}$. (P, cortical plate.

mained significantly reduced in LPS-challenged mice $(p=$ 0.031; Fig. 1D). The fraction of IdU-positive cells that reentered S-phase to become double labeled for IdU and CldU was also reduced ( $p=0.049$; Fig. $1 D$ ), and there was a corresponding increase in quit fraction, the fraction of IdU-positive cells that exited the cell cycle to become Ki67 negative ( $p=$ 0.0014; Fig. 1D).
Tissues were also stained for phosphorylated histone $\mathrm{H} 3$ ( $\mathrm{pHH} 3$-positive), a marker for cells in metaphase. We have previously reported that the number of pHH3-positive cells is reduced in the fetal brain during the hypoxic challenge (Carpentier et al., 2011), and Herr et al. (2011) have shown that $\mathrm{pHH} 3$-positive cells become displaced and are proportionally more abundant in the intermediate zone (IZ) in a prenatal hypoxia model. In the present study, the location of $\mathrm{pHH} 3$ positive cells was scored and the ratio of ventricular zone (VZ) to IZ $\mathrm{pHH} 3$ positive cells was determined (Fig. $1 E, F$ ). Although some animals showed an increase in pHH3-positive cells in the IZ, the change in group mean was not statistically significant.

Brain and body weight are normal at birth but diverge with age

To determine whether decreased proliferative activity of neural progenitors resulted in smaller brains at birth or in the adult, pregnant mice were challenged with LPS at E12.5 and pregnancies were allowed to proceed to term. All pups were fostered to untreated wild-type mothers at birth. Pups from saline and LPSchallenged pregnancies had similar body mass at birth (P0), indicating that the challenge was not sufficient to restrict intrauterine growth. However, body weights began to diverge in the following weeks (Fig. 2A). LPS-exposed offspring gained weight more slowly and achieved lower adult body weights for the duration of monitoring (2-4 months). Both male and female mice were equally affected (data not shown). Brain weights were reduced relative to controls at $\mathrm{P} 7$ but not P28 (Fig. 2B). The ratio of brain to body weight was slightly higher at P7 but similar between groups at P28 (Fig. 2C).

\section{Alterations in adult laminar distribution of neurons produced at} E12.5 and E15.5

Cortical development follows a stereotyped inside-out progression with deeper layer neurons born first. Neurons born later in gestation migrate past the inner layers to sequentially populate the outer layers of the cortex. Neuronal subtype patterning in the $\mathrm{VZ}$ changes over time to generate the functionally and morphologically distinct neuronal subtypes of each lamina (Molyneaux et al., 2007). The abundance of each neuronal subtype and the relative positioning of cells within the cortical lamina may both be important for function. Accordingly, cortical tissues were evaluated two ways: tissues were first scored for cell density in all lamina and then scored for the distribution of cells among 10 equally distributed laminar zones or "bins" (laminar distribution). 
A

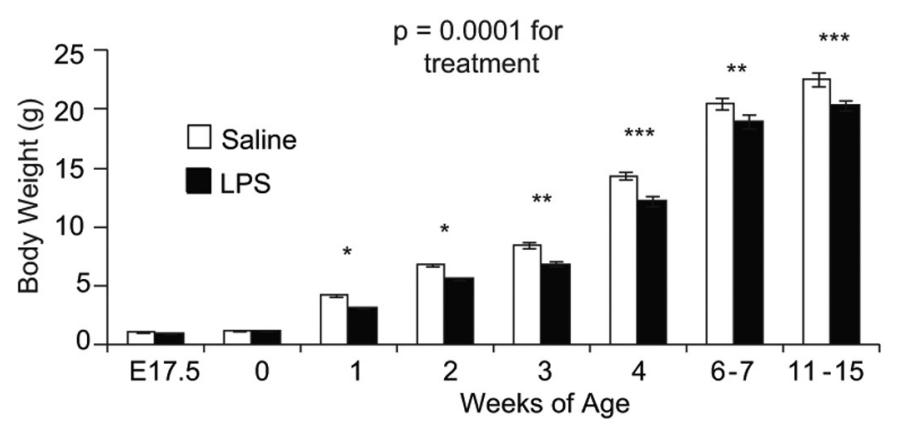

B

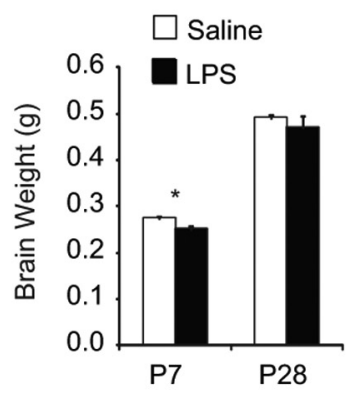

C

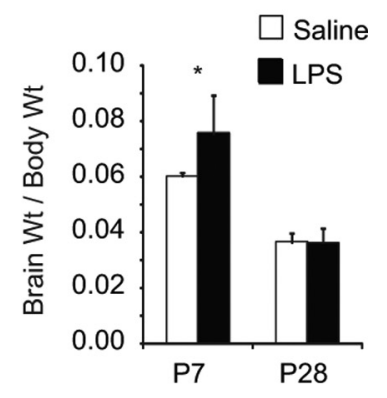

Figure 2. Decreased brain and body size in LPS-exposed mice. Pregnant mice were treated with saline or LPS (60 $\mu \mathrm{g} / \mathrm{kg})$ at E12.5. At birth, offspring were fostered to naive mothers. $A$, 0 ffspring were weighed at the indicated times. There was a significant effect of treatment $(p<0.0001)$ and interaction between treatment and age $(p=0.0025)$ by two-way AN0VA* $p<0.05,{ }^{* *} p<0.01$, and ${ }^{* * *} p<0.001$ by Bonferroni post hoc test, $n=18-31$ from at least four pregnancies per time point. $\boldsymbol{B}$, At P7 or P28, mice were weighed and brains were harvested and weighed. Mice from the LPS group showed reduced brain weight at P7 ( ${ }^{*} p=0.02$, two-tailed Student's $t$ test) but no significant difference at P28, $n=19$ saline from four pregnancies and 7 LPS from three pregnancies at P7, P9 saline from two pregnancies and 5 LPS from two pregnancies at P28. C, Brain/body weight ratios were slightly increased at P7 ( ${ }^{*} p=0.03$, two-tailed Student's $t$ test) but not statistically different at P28, $n=9$ saline from three pregnancies and 4 LPS from two pregnancies at P7, P9 saline and 5 LPS from two pregnancies each at P28.

To determine whether in utero challenge altered cell abundance and/or laminar positioning of cells born during the peak immune effects at E12.5 or $3 \mathrm{~d}$ later at E15.5, pregnant mice were injected with LPS or saline at E12.5. Two hours later, when the effects on fetal perfusion and the resulting hypoxia were most significant, animals were injected with IdU to label cells dividing during the challenge. Animals were subsequently injected with CldU at E15.5 to label neural progenitors dividing $3 \mathrm{~d}$ after the challenge, when fetal perfusion had normalized (Carpentier et al., 2011). Pregnancies were allowed to proceed to term and offspring were fostered to unmanipulated mothers. At 4 weeks of age, brains were collected from offspring and coronal sections were stained for IdU, CldU, or markers that identify several common projection neuron subtypes (Figs. 3, 4).

Semiserial sections spanning the motor and somatosensory cortex were first scored for gross anatomical alterations (Fig. $3 A$ ). The linear thickness of the cortex between the pia and dorsal surface of the corpus callosum (CC) was measured perpendicular to pia at three evenly spaced anterior to posterior locations (Fig. $3 A, B)$. LPS challenge at E12.5 resulted in a significant physical thinning of cortical structures relative to saline-treated controls (Fig. 3A; effect of treatment, $p=0.02$ ).

Sections from P28 brains were next scored for the relative abundance and laminar positioning of nuclei labeled with IdU at E12.5 or with CldU at E15.5 (Fig. 3B-I). Cell abundance was scored across the entire cortex from pia to dorsal surface of the $\mathrm{CC}$ and within 10 equally distributed laminar zones or bins (Fig. $3 B$ ). Bin 1 is approximately equivalent to cortical layer I. The normal distribution of cells born at E12.5 and E15.5 is shown for saline controls (Fig. 3C), which illustrates the natural positioning of E12.5-born cells to the inner cortical layers (bins $6-10)$ and the positioning of E15.5-born cells to the outer cortical layers (bins 1-5).

Although proliferative activity of neural progenitors was reduced in utero, the abundance of E12.5-labeled IdU-positive cells in adult was not statistically altered by LPS challenge (Fig. 3D). However, the laminar distribution of cells detected was significantly disrupted with a depletion of E12.5-born cells from inner layers and an over-representation in outer layers (Fig. 3E, Tables $1,2)$. The relative depletion or over-representation in each lamina is more readily visualized as the natural log of the fold change relative to saline controls (Fig. $3 F$ ). The superficial-most bin corresponding to the marginal zone-derived layer I of the cortex diverged from this trend and was significantly depleted of E12.5born cells.

The overall density of CldU-positive cells labeled at E15.5 was also unchanged by LPS challenge (Fig. $3 G$ ), but laminar distribution was altered in a pattern opposite to the laminar displacement of IdU-positive cells born 3 d earlier (Fig. 3 H, I, Tables 1, 2). CldUpositive cells born at E15.5 were significantly under-represented in superficial layers and over-represented in deep layers of the cortex. As with IdU-positive cells, the distribution of CldU-positive cells in the marginal zone-derived cortical bin 1 was distinct from the other superficial bins and showed an increase in abundance, opposite to the LPS-induced decrease in IdU-positive cells in the same region of the cortex.

The changes in laminar positioning of E12.5- and E15.5-born cells suggested that the cellularity might also be altered in deep versus superficial layers of the cortex. The laminar position of each cell nucleus, independent of cell type or birth date, was recorded and cell densities were calculated for the entire cortical thickness (Fig. 3J). Although brain weights were lower and cortical structures were thinner, the overall cell density and laminar distribution of nuclei within the cortex was not significantly altered by LPS challenge (Fig. $3 K, L$ ).

\section{Alterations in projection neuron abundance and laminar distribution}

Cortical tissues were next evaluated for the abundance of cortical projection neurons expressing Ctip2, Satb2, Tbr1, or Cux1 (Fig. 4). The density of labeled projection neurons was first scored for the entire cortical thickness, independent of laminar position, and statistical significance was evaluated by Student's $t$ test. Counts were then broken down into 10 laminar bins and evaluated for all 10 laminar bins together or separately for superficial (1-5) or deep layer bins (6-10). The LPS-induced change in cell density (LPS cells $/ \mathrm{mm}^{2}-$ saline cells $/ \mathrm{mm}^{2}$ ) was also calculated and presented as the difference in cell density for each bin.

LPS challenge had no significant impact on the overall density of Ctip2-positive subcortical projection neurons (Fig. 4A), but analysis of cell density by laminar bin did reveal a significant treatment effect causing an increase in the abundance of Ctip2-positive cells in superficial cortical layers (Fig. 4B, statistics in Table 1). Presenting the change in density for each laminar bin as a net loss or gain of cells per $\mathrm{mm}^{2}$ in each bin highlights the relative increase in outer layers of the cortex 
A
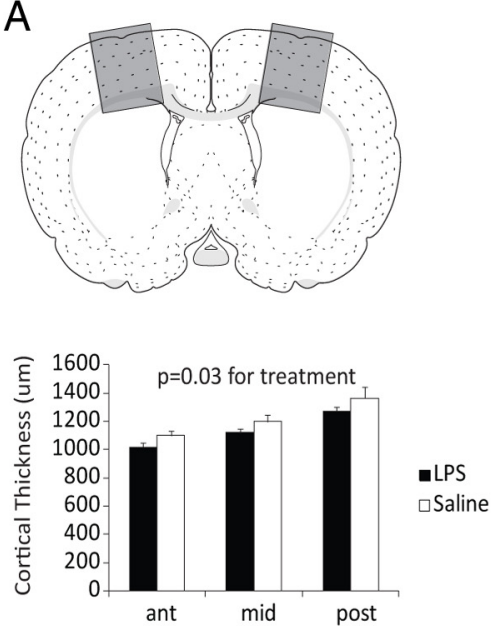

D

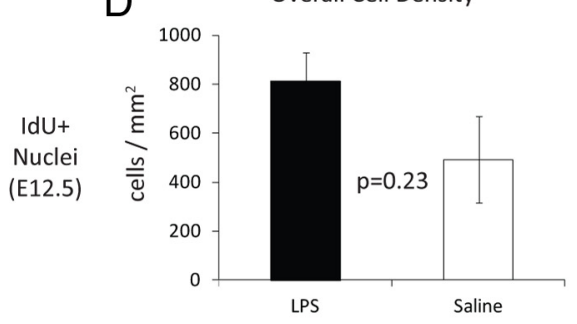

G
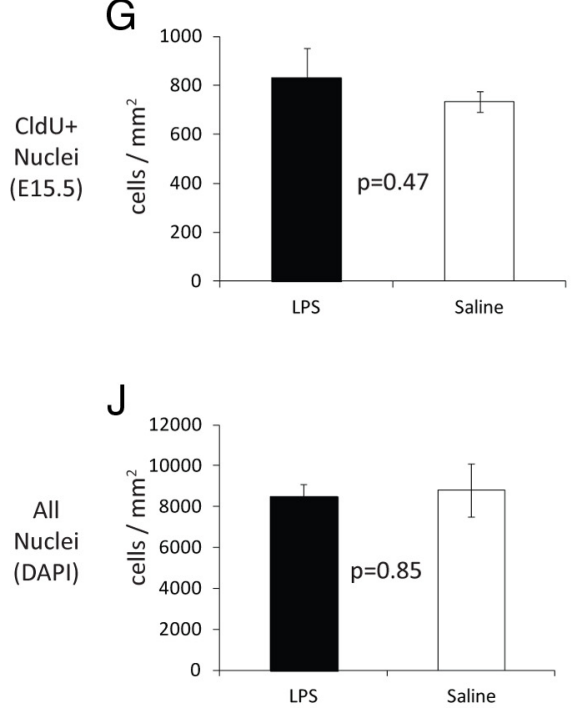

B

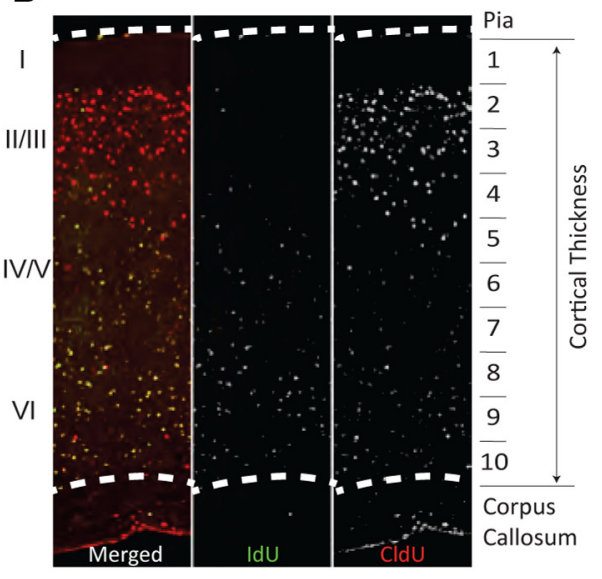

C

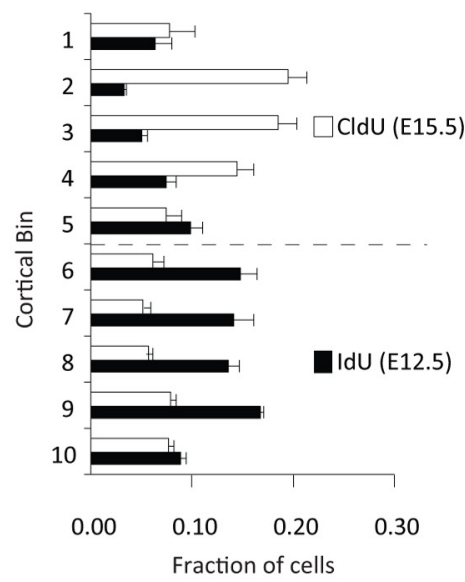

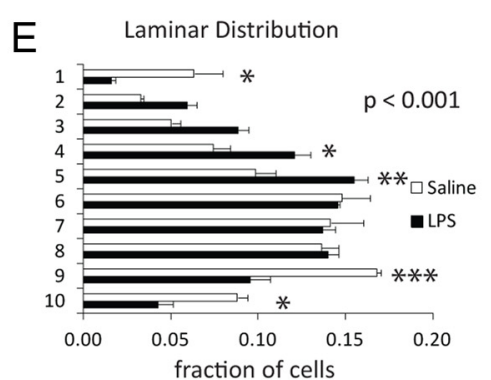

$\mathrm{H}$

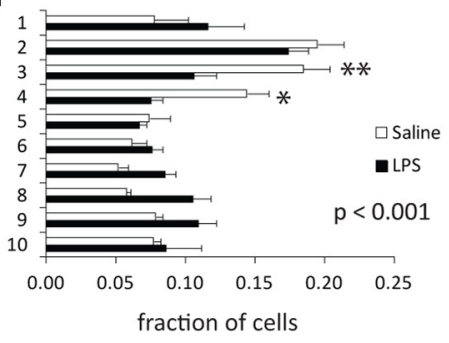

K

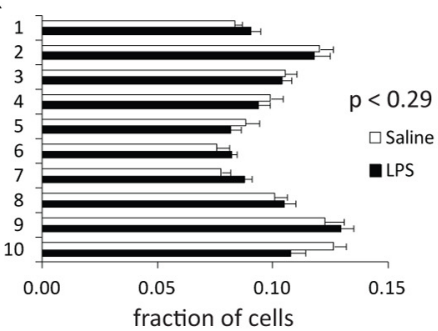

Effect of LPS on

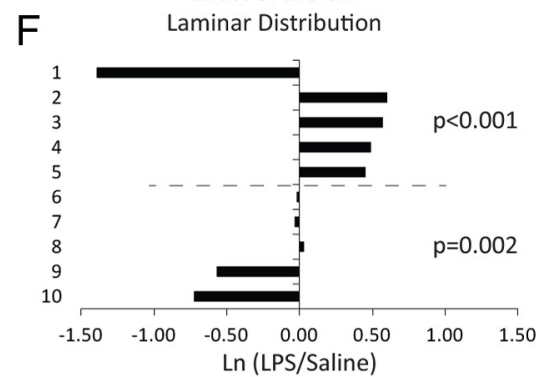

I

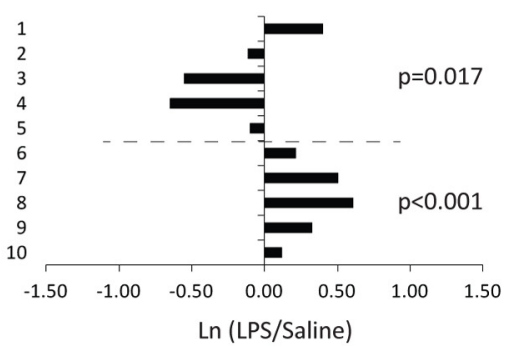

L

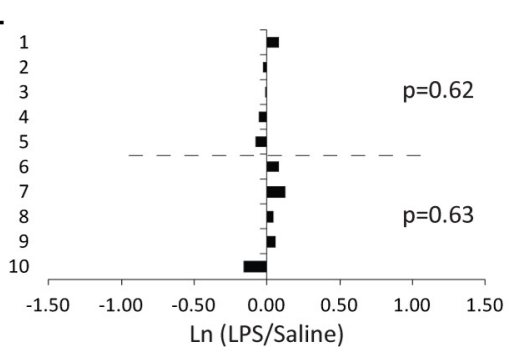

Figure 3. Cellularity and cellular birthdates in the cortex of adult offspring. Pregnant mice were treated with saline or LPS ( $60 \mu \mathrm{g} / \mathrm{kg})$ at E12.5. At birth, offspring were fostered to naive mothers, and brains of offspring were harvested at P28.A, A schematic drawing of a mouse coronal brain section showing boxed areas of somatosensory and motor cortex that were evaluated in these studies. Cortical thickness was measured in P28 mice as the distance between pia and (C in three semiserial sections ( $960 \mu \mathrm{m}$ intervals), beginning at the head of the dorsal lateral ventricles and extending caudally to approximately the hippocampal commissure. Cortical areas were sampled at $\sim 1 \mathrm{~mm}$ lateral from the midline. Mice from the LPS treatment group showed a decrease in cortical thickness ( ${ }^{*} p=0.03$ effect of treatment, two-way ANOVA, $n=5$ from 3 pregnancies). $\boldsymbol{B}$, An example adult cortex stained for IdU-positive cells generated at E12.5 (green) and (IdU-positive cells generated at E15.5 (red). Also shown are the relative positions of major cortical lamina and the division of the cortex into 10 equal bins for positional scoring of cell location. Bin 1 is located in superficial layer I of the cortex and bin 10 is located in the ventral-most region of layer VI. C, Fraction of IdU- and CIdU-positive cells located in each laminar bin shows the normal segregation of E12.5-born cells to bins $6-10$ and E15.5-born cells to bins $1-5$ in saline controls. $\boldsymbol{D}$, The density of IdU + cells in all lamina ( $p=0.23$, two-tailed Student's $t$ test, $n=4)$. $\boldsymbol{E}$, The laminar distribution of IdU + cells in saline or LPS treatment groups $(n=4), p$ value for treatment is shown and Bonferroni post hoc significance indicated by ${ }^{*} p<0.05,{ }^{* *} p<0.01$, and ${ }^{* * *} p<0.001$. $\boldsymbol{F}$, The relative LPS-induced change in distribution calculated as the $\operatorname{Ln}($ LPS/Saline) for values shown in $E$. The $p$ values are listed for treatment effects calculated separately for bins $6-10$ and $1-5$, corresponding to the laminar bins containing the majority of cells labeled during the inflammatory challenge at E12.5 (bins $6-10$ ) or $3 \mathrm{~d}$ after the inflammatory challenge at E15.5 (bins $1-5$ ). $\mathbf{G}-\mathbf{I}$, The density and laminar distribution of CldU-positive cells. $J-L$, The density and laminar distribution of all nuclei within the cortex. Complete two-way ANOVA values for cell density and relative laminar distribution are provided in Tables 1 and 2, respectively. 

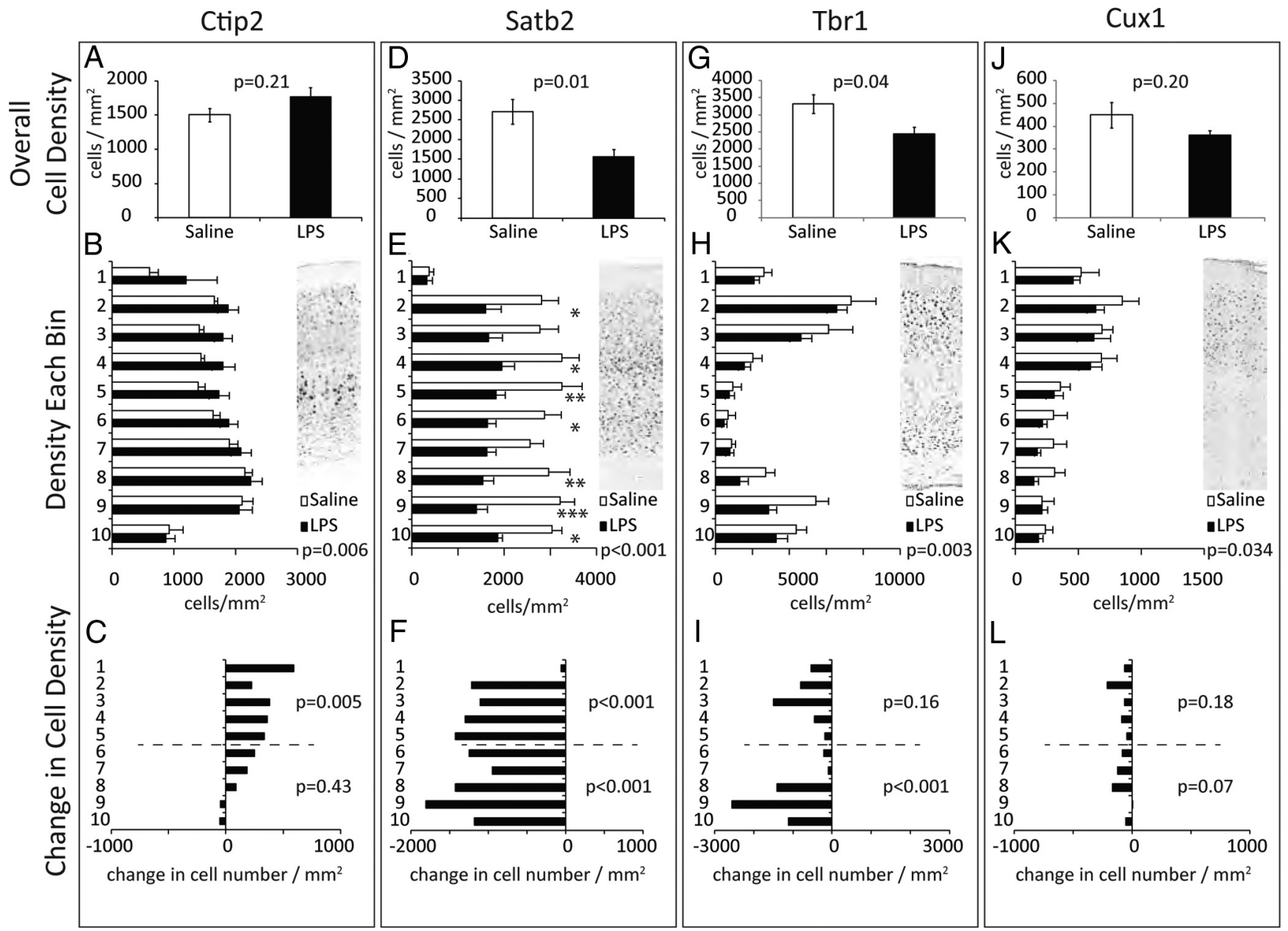

$\mathrm{M}$

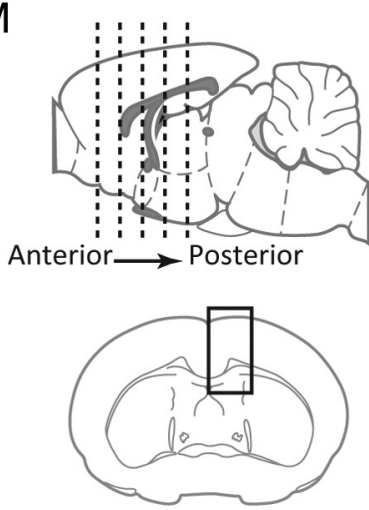

$\mathrm{N}$

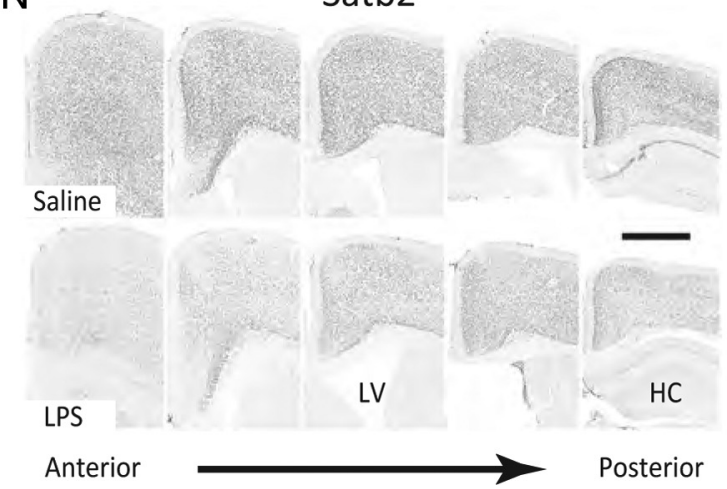

Satb2

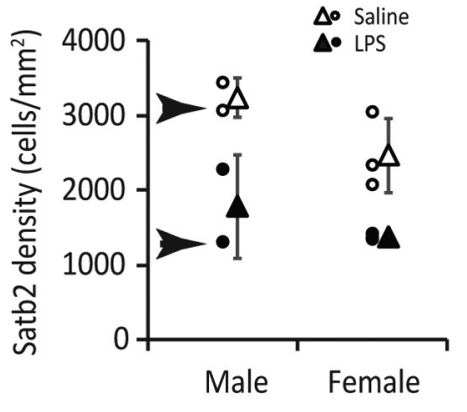

Figure 4. Projection neuron abundance and laminar distribution. Pregnant mice were treated with saline or LPS ( $60 \mu \mathrm{g} / \mathrm{kg})$ at E12.5. At birth, offspring were fostered to naive mothers. Brains were harvested at P28, sectioned, and stained for Ctip2 $(\boldsymbol{A}-\boldsymbol{C})$, Satb2 (D-F), $\operatorname{Tbr} 1(\boldsymbol{G}-\boldsymbol{I})$, or Cux1 $(\boldsymbol{J}-\boldsymbol{L}), n=5$ from three pregnancies. $\boldsymbol{A}, \boldsymbol{D}, \boldsymbol{G}, \boldsymbol{J}$, The density of each cell type was calculated for all cortical lamina combined. Indicated $p$ values are for two-tailed Student's $t$ test. $B, E, H, K$, The density of cells within 10 equally spaced laminar regions of the cortex. The inset shows a representative full-thickness cortical area stained for each marker. The $p$ values for treatment by two-way ANOVA are shown, Bonferroni post hoc significance ${ }^{*} p<0.05,{ }^{* *} p<0.01$, and ${ }^{* * *} p<0.001$. $C, F, I, L$, The change in cell density (cells $/ \mathrm{mm}^{2}$ ) for each bin in LPS-challenged compared with saline controls (LPS cells $/ \mathrm{mm}^{2}-$ Saline cells $/ \mathrm{mm}^{2}$ ). The $p$ values indicate two-way ANOVA analysis of treatment on cell density in bins 1-5 or 6-10. Complete two-way ANOVA results for cell density are provided in Table 1. $M, N$, Visual comparison of Satb2 staining from frontal to caudal cortex. Coronal sections were selected throughout the A-P axis of the cortex and micrographs collected in the superior cortex as illustrated in $\boldsymbol{M}$. Cortical samples from two mice are shown in $\boldsymbol{N}$. The central sulcus is aligned to the left side of each image. LV, lateral ventricle; HC, hippocampal formation. Scale bar, $500 \mu \mathrm{m}$. $\mathbf{0}$, Average Satb2 density for individual mice scored in $\mathbf{D}-\boldsymbol{F}$ and $\mathbf{N}$. 0 pen and closed circles represent individual animal data points. Triangles $=$ mean \pm SD for each sex and treatment group. Sections shown in $\boldsymbol{N}$ are from the individual mice indicated by arrows in $\mathbf{0}$.

(Fig. 4C). Satb2-expressing neurons are born concurrently with Ctip2-positive neurons but send commissural projections to contralateral cortical targets rather than subcortical targets (Alcamo et al., 2008). LPS challenge caused a significant reduction the abundance of Satb2-labeled cells with ef- fects observed in both superficial and deep layers of the cortex (Fig. 4D-F; ANOVA statistics in Table 1). Tbr1-positive neurons were also significantly depleted in LPS-challenged mice with the largest impact on deep layer neurons born concurrent with the LPS challenge (Fig. 4G-I, Table 1). Cux1-positive 
Table 1. ANOVA for treatment effects on cell density in the cortex

\begin{tabular}{|c|c|c|c|c|c|c|}
\hline & \multicolumn{2}{|c|}{ All layers (bins 1-10) } & \multicolumn{2}{|c|}{ Superficial layers (bins 1-5) } & \multicolumn{2}{|c|}{ Deep layers (bins 6-10) } \\
\hline & $p$ value & $F[\mathrm{DFn}, \mathrm{DFd}]$ & $p$ value & $F[\mathrm{DFn}, \mathrm{DFd}]$ & $p$ value & $F[\mathrm{DFn}, \mathrm{DFd}]$ \\
\hline \multicolumn{7}{|l|}{$\overline{\text { DAPI }}$} \\
\hline Treat & 0.237 & $1.42[1,80]$ & 0.1815 & $1.85[1,40]$ & 0.802 & $0.06[1,40]$ \\
\hline Inter & 0.867 & $0.50[9,80]$ & 0.9483 & $0.18[4,40]$ & 0.491 & $0.09[4,40]$ \\
\hline \multicolumn{7}{|l|}{ IdU } \\
\hline Treat & $<\underline{0.001}$ & $14.67[1,80]$ & 0.002 & $11.45[1,40]$ & 0.031 & $5.13[1,40]$ \\
\hline Inter & 0.118 & $1.66[9,80]$ & 0.021 & $3.39[4,40]$ & 0.402 & $1.04[4,40]$ \\
\hline \multicolumn{7}{|l|}{ CldU } \\
\hline Treat & 0.323 & $0.99[1,80]$ & 0.7822 & $0.08[1,40]$ & $<\underline{0.001}$ & $16.14[1,40]$ \\
\hline Inter & 0.651 & $0.76[9,80]$ & 0.6783 & $0.58[4,40]$ & 0.768 & $0.68[4,40]$ \\
\hline \multicolumn{7}{|l|}{ Ctip2 } \\
\hline Treat & 0.006 & $7.99[1,80]$ & 0.005 & $8.99[1,40]$ & 0.426 & $0.65[1,40]$ \\
\hline Inter & 0.788 & $0.61[9,80]$ & 0.922 & $0.23[4,40]$ & 0.844 & $0.35[4,40]$ \\
\hline \multicolumn{7}{|l|}{ Satb2 } \\
\hline Treat & $<\underline{0.001}$ & $88.05[1,80]$ & $<\underline{0.001}$ & $29.22[1,40]$ & $<\underline{0.001}$ & $65.50[1,40]$ \\
\hline Inter & 0.239 & $1.33[9,80]$ & 0.169 & $1.71[4,40]$ & 0.553 & $0.77[4,40]$ \\
\hline \multicolumn{7}{|l|}{ Tbr1 } \\
\hline Treat & 0.003 & $9.43[1,80]$ & 0.161 & $2.04[1,40]$ & 0.001 & $12.00[1,40]$ \\
\hline Inter & 0.695 & $0.71[9,80]$ & 0.930 & $0.21[4,40]$ & 0.106 & $2.05[4,40]$ \\
\hline \multicolumn{7}{|l|}{ Cux1 } \\
\hline Treat & 0.034 & $4.62[1,80]$ & 0.181 & $1.85[1,40]$ & 0.074 & $3.37[1,40]$ \\
\hline Inter & 0.991 & $0.22[9,80]$ & 0.946 & $0.18[4,40]$ & 0.823 & $0.38[4,40]$ \\
\hline \multicolumn{7}{|l|}{ GABA } \\
\hline Treat & 0.286 & $1.16[1,80]$ & 0.140 & $2.27[1,40]$ & 0.896 & $0.02[1,40]$ \\
\hline Inter & 0.924 & $0.42[9,80]$ & 0.909 & $0.26[4,40]$ & 0.876 & $0.30[4,40]$ \\
\hline \multicolumn{7}{|l|}{ PV } \\
\hline Treat & 0.020 & $5.65[1,80]$ & 0.247 & $1.38[1,40]$ & 0.017 & $6.20[1,40]$ \\
\hline Inter & 0.957 & $0.35[9,80]$ & 0.839 & $0.36[4,40]$ & 0.820 & $0.38[4,40]$ \\
\hline \multicolumn{7}{|l|}{ Calret } \\
\hline Treat & 0.495 & $0.47[1,80]$ & 0.267 & $1.26[1,40]$ & 0.304 & $1.08[1,40]$ \\
\hline Inter & 0.982 & $0.27[9,80]$ & 0.996 & $0.05[4,40]$ & 0.991 & $0.07[4,40]$ \\
\hline \multicolumn{7}{|l|}{ Calb } \\
\hline Treat & 0.208 & $1.61[1,80]$ & 0.216 & $1.58[1,40]$ & 0.851 & $0.04[1,40]$ \\
\hline Inter & 0.391 & $1.07[9,80]$ & 0.399 & $1.04[4,40]$ & 0.963 & $0.15[4,40]$ \\
\hline \multicolumn{7}{|l|}{ Reelin } \\
\hline Treat & 0.298 & $1.10[1,80]$ & 0.318 & $1.02[1,40]$ & 0.688 & $0.16[1,40]$ \\
\hline Inter & 0.998 & $0.15[9,80]$ & 0.987 & $0.08[4,40]$ & 0.932 & $0.21[4,40]$ \\
\hline
\end{tabular}

Two-way ANOVA was used to evaluate treatment effects (Treat) or interaction between treatment and bin (Inter) on cell density (cells/mm ${ }^{2}$ ) across all bins or calculated separately for the subset of five bins located in superficial or deep layers of the cortex. Values that reach a statistical significance of $p<0.05$ are underlined.

Table 2. ANOVA for treatment effects on laminar distribution

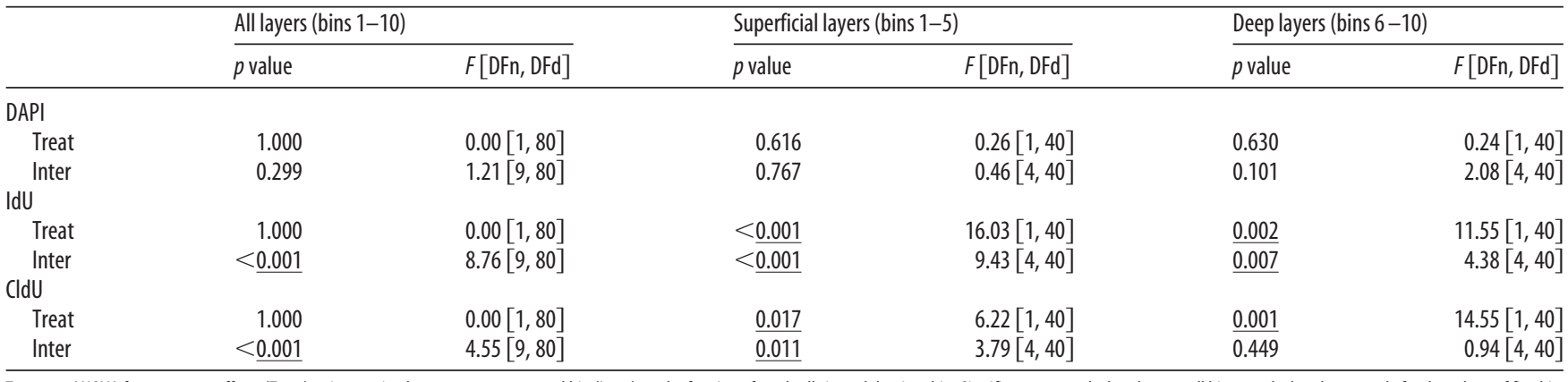

Two-way ANOVA for treatment effects (Treat) or interaction between treatment and bin (Inter) on the fraction of total cells in each laminar bin. Significance was calculated across all bins or calculated separately for the subset of five bins located in superficial or deep layers of the cortex. Values that reach a statistical significance of $p<0.05$ are underlined.

neurons, which are born later in development, were not significantly affected (Fig. $4 J-L$ ).

The effects on Satb2-positive neurons were so pronounced that four of five LPS-challenged offspring that were scored could be correctly identified and separated based on a simple visual evaluation of the confocal micrograph (Fig. 4M-O, Satb2 density for individual animals). The fifth LPS-challenged animal that could not be identified by eye had numerically normal Satb2 neuronal densities, suggesting that some siblings remain unaffected following in utero challenge. The reduction in Satb2-positive neurons in LPS- challenged animals relative to saline control animals is notable throughout the A-P axis of the cortex. Of the five animals scored, two in each group were male and three were female. All three females and one male from the LPS group showed reduced Satb2 density while one male had normal Satb2 densities.

\section{Alterations in CC and cortical neuron projections}

Ctip2, Satb2, and Tbr1 are transcriptional regulators that are required for the developmental specification of subcerebral (Ctip2) or cerebral projection neurons (Satb2, Tbr1) (Alcamo et 
A

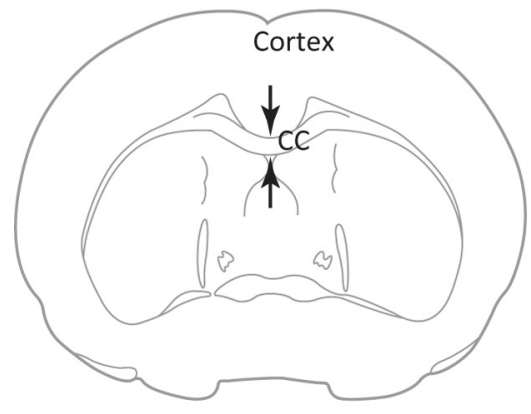

D

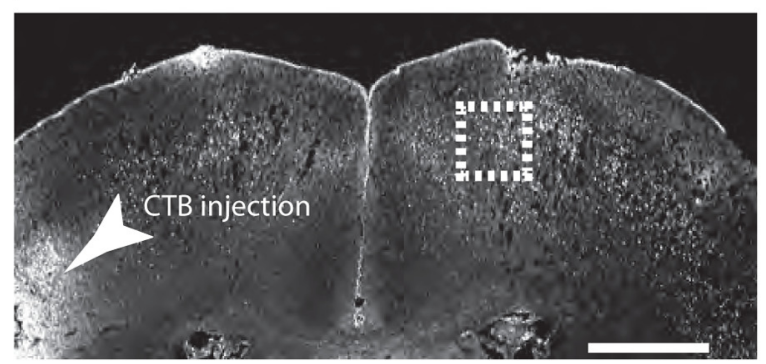

B

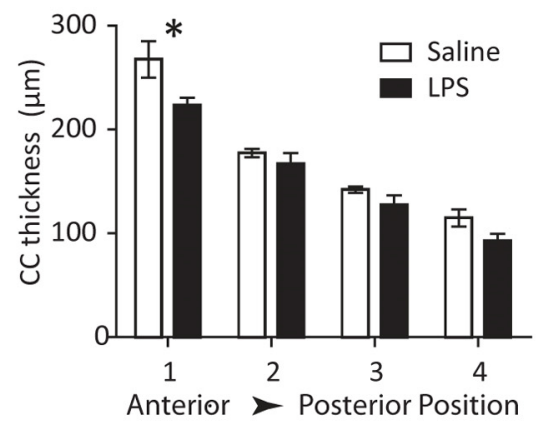

$E$

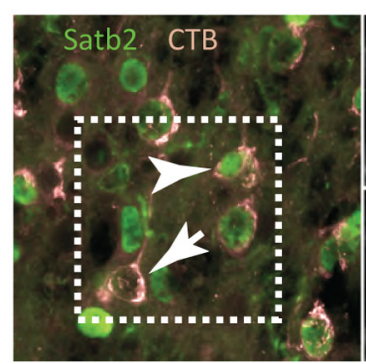

C

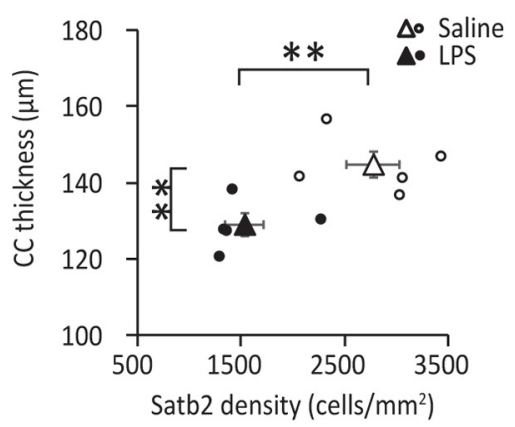

$\mathrm{F}$

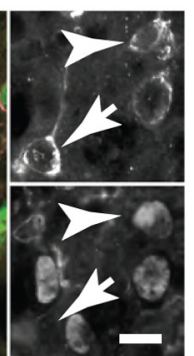

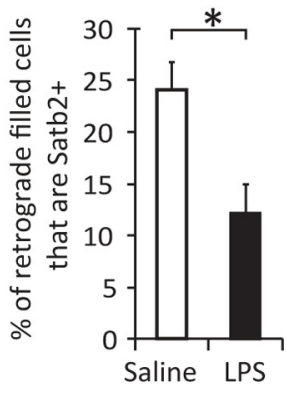

Figure 5. Alterations in callosal thickness and projections. $\boldsymbol{A}, \boldsymbol{B}$, The thickness of the C $C$ was measured at the midline in P28 brains. Offspring from LPS-challenged pregnancies showed a significant treatment effect with the most pronounced thinning observed in anterior sections (two-way ANOVA, $F_{(3,27)}=1.18$, treatment $p<0.01,{ }^{*} p<0.05$ by Bonferroni $p$ ost hoc). $C$, Average callosal thickness was compared with Satb2 density for each animal. Open and closed circles represent individual animal data points. Triangles $=$ mean $\pm S E M$ for each treatment group. ${ }^{* *} p<0.01$ by two-tailed Student's $t$ test for the indicated measures. D, Fluorescent cholera toxin $\beta$ (CTB) was injected unilaterally into P6 pups and mice were killed $3 \mathrm{~d}$ later. Contralateral cortex was evaluated for retrograde-labeled cell bodies (boxed area). CTB injection site indicated by arrowhead. Scale bar, $500 \mu \mathrm{m}$. E, Colocalization of CTB-filled cell bodies (red) with Satb2 immun ofluorescence (green). Arrowhead shows CTB-filled Satb2-positive neuron. Arrow shows CTB-filled Satb2-negative neuron. Scale bar, $10 \mu \mathrm{m}$. $\boldsymbol{F}$, The fraction of retrogradely labeled cells that were Satb2-positive was scored in the contralateral cortex. ${ }^{*} p<0.05$ by two-tailed Student's $t$ test.

al., 2008; Leone et al., 2008; Bedogni et al., 2010; McKenna et al., 2011). The significant reduction in Satb2-positive neurons suggested that commissural and callosal connectivity to the contralateral cortex may be reduced. Callosal thickness was measured and found to be significantly reduced in LPS-challenged offspring with the most pronounced reduction in anterior sections (Fig. 5A,B). Callosal thickness averaged across all sections also showed a significant correlation to Satb2 neuronal density (Fig. 5C). When individual animal data points were pooled for both treatment groups, a one-way Pierson correlation indicates decreased CC thickness with decreased Satb2 density $(p=0.03$, $n=10)$.

To determine whether there was a corresponding reduction in the fraction of corticocortical projection neurons that are Satb2 positive, new cohorts of saline or LPS-challenged mice were generated and fluorescent CTB was injected unilaterally into the P6 cortex. Brains were harvested $72 \mathrm{~h}$ later and retrogradely filled neurons in the contralateral cortex scored for Satb2 (Fig. 5D-F). In utero challenge with LPS resulted in a $50 \%$ reduction in the fraction of projecting cells that are Satb2-positive.

\section{Alterations in interneuron abundance and laminar distribution}

Interneurons are also produced at the time of inflammatory challenge but migrate laterally from the ganglionic eminences to populate cortical regions. The abundance and distribution of GABA-positive cells was not significantly altered in the LPSchallenged group (Fig. 6A-C, Table 1). Parvalbumin (PV)positive interneurons show near-significant reductions overall
(Fig. 6D) and analyzing cell density across the 10 laminar bins revealed a significant treatment effect indicating a depletion that was most pronounced in deep layers (Fig. 6E, F, Table 1). Calretinin (CR)-positive cell abundance was not altered overall (Fig. $6 G-I$, Table 1$)$. The density of calbindin-positive or reelinpositive interneurons was also unaffected (Fig. 6J-O, Table 1).

\section{Alterations in adult behavior}

Offspring were tested for alterations in social behavior, olfactory function, associative learning and memory, general locomotion, open field exploration, and acoustic startle, and sensory motor gating in the PPI test.

Social behavior (both social interaction and social memory) was tested using an adaptation of the three-chamber social interaction paradigm (Crawley, 2007). The amount of time spent in each chamber during the habituation phase of the test was examined, and we found there was a significant effect of chamber position but not treatment (Fig. $7 B ; p<0.001, p=0.22$, respectively). This result was due to less time spent in the middle chamber, which contained no pencil cup. The analysis of all mice in both groups confirms a significant preference for the chambers containing empty pencil cups $(p<0.05$ for empty vs middle and empty vs mouse) but no significant bias in the time spent in the outer chamber that would contain the mouse or the empty cup. The increased time spent in the outer chambers but lack of treatment effect is consistent with both groups showing normal interactions with a novel inanimate object.

In the sociability phase of testing, a stimulus mouse was placed under a pencil cup in one of the outer chambers, and the test 

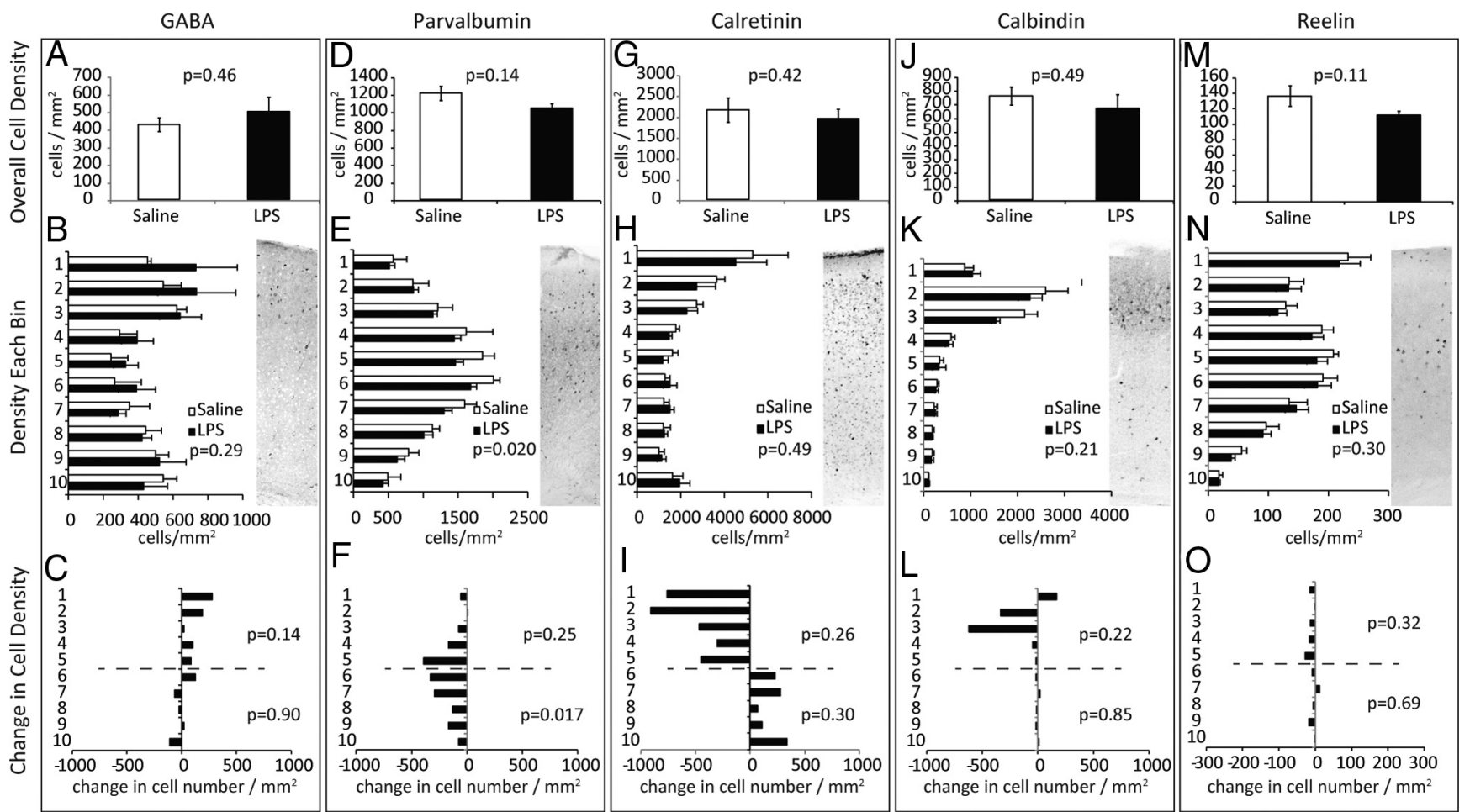

Figure 6. Interneuron abundance and laminar distribution. P28 brains were stained for GABA $(\boldsymbol{A}-\boldsymbol{C}), \mathrm{PV}(\boldsymbol{D}-\boldsymbol{F}), \mathrm{CR}(\boldsymbol{G}-\boldsymbol{I})$, calbindin $(\boldsymbol{J}-\boldsymbol{L})$, or Reelin $(\boldsymbol{M}-\mathbf{0}), n=5$ from three pregnancies. $\boldsymbol{A}, \boldsymbol{D}$, $\boldsymbol{G}, \boldsymbol{J}, \boldsymbol{M}$, The overall density of immunopositive cells was determined for each marker. The significance in overall cell density was tested by two-tailed Student's $t$ test. $\boldsymbol{B}, \boldsymbol{E}, \boldsymbol{H}, \boldsymbol{K}, \boldsymbol{N}$, The density of cells within 10 equally spaced laminar regions of the cortex. The inset shows a representative stain for each marker. $C, F, I, L, O$, The change in cell density per bin in LPS-challenged compared with saline controls. Complete two-way ANOVA data for cell density is provided in Table 1.

subject was allowed to explore all three chambers for $10 \mathrm{~min}$. The time to initiate contact with the stimulus mouse as well as the total amount of time spent sniffing the mouse or the empty cup were recorded. Mice from control or LPS-challenged pregnancies showed equivalent latency to the first contact with the stimulus mouse (Fig. 7C). Mice from both groups showed a significant increase in the time spent sniffing the novel mouse compared with the familiar empty cup ( $p<0.0001$ for both saline and LPS), but mice exposed to a prenatal immune event spent less total time interacting with the stimulus mouse (Fig. $7 D ; p=0.030$, Student's $t$ test). Closer examination of behavior during the early, middle, and late periods of the $10 \mathrm{~min}$ trial revealed a significant gender bias with selective effects in males (Fig. 7E; $p=0.005$ treatment effect). Treatment effects did not reach significance for female mice (Fig. 7F; $p=0.19$ treatment effect).

In the social memory phase of testing, the original stimulus mouse (familiar mouse) is moved to the opposite chamber and a novel mouse placed in the opposite chamber. Saline and LPS treatment groups both preferred interacting with the novel mouse and there was no significant difference between groups (Fig. 7G). This indicates that prenatal challenge caused alterations in sociability but not in the animal's ability to recognize the novel versus previously introduced mouse. A buried food test confirmed that olfactory function was normal in both groups and did not play a role in altered sociability (mean latency to find food, $19.5 \pm 2.0 \mathrm{~s}$ for saline, $15.6 \pm$ $2.2 \mathrm{~s}$ for LPS, $p=0.59$, two-tailed Student's $t$ test ).

A separate cohort of mice was tested for alterations in associative processing, learning, and memory in the DMP water maze task (Steele and Morris, 1999). In the DMP task, a hidden escape platform is placed in a new location on consecutive training days. Each day, animals must first locate the platform and then remember its location in the subsequent trials (Fig. 8A). Offspring from
LPS-challenged pregnancies were able to learn the paradigm but did not reach the same proficiency as saline controls (Fig. 8B). Average latency to find the platform on trials 1-6 (averaged across days 2-13) showed significant impairment in the LPSchallenged group ( $p=0.04$ for treatment) with trial bins $4-6$ showing significant delay in time to find the platform This effect was primarily due to alterations in male mice. Animals also showed an increase in thigmotaxia (Treit and Fundytus, 1988) or time spent swimming along the wall of the pool (Fig. $8 C ; p=0.02$ for treatment). The effects were most pronounced in male animals. Other indicators of learning showed subtle male-specific reduction in the number of times animals returned to the previous day's platform (Fig. $8 D$ ) or the number of times mice came close to the new platform position but narrowly missed (less often in LPS-challenged animals, Fig. $8 E$ ). There were no significant differences in swim speed, but male animals showed a trend toward reduced swim velocity in trial bins 1 and 2 (Fig. $8 F$ ), when males showed the greatest tendency to swim along the rim of the pool (Fig. $8 C$ ). There were no significant differences in latency to find a visible platform for either male or female LPS-challenged animals (data not shown).

A third cohort of mice was tested for alterations in acoustic startle and sensory motor gating using the PPI test. LPSchallenged animals displayed a reduced acoustic startle response relative to controls (Fig. $9 A ; p=0.002$ for treatment), as well as a slight but nonsignificant reduction in the percentage PPI (Fig. $9 B$ ). The effect on acoustic startle was not significantly different between males and females (data not shown).

Open field exploration showed no significant differences in exploratory behavior or locomotor activity (Fig. 10). An increase in thigmotaxia noted in the water maze task was not observed in the open field task, and there was no significant increase in time or 
A

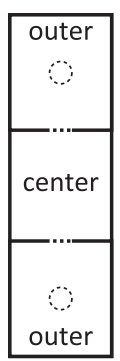

E

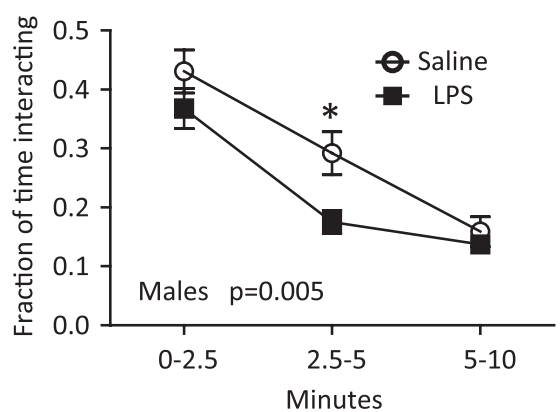

C

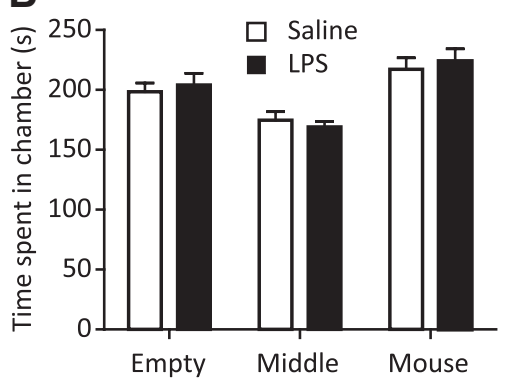

F
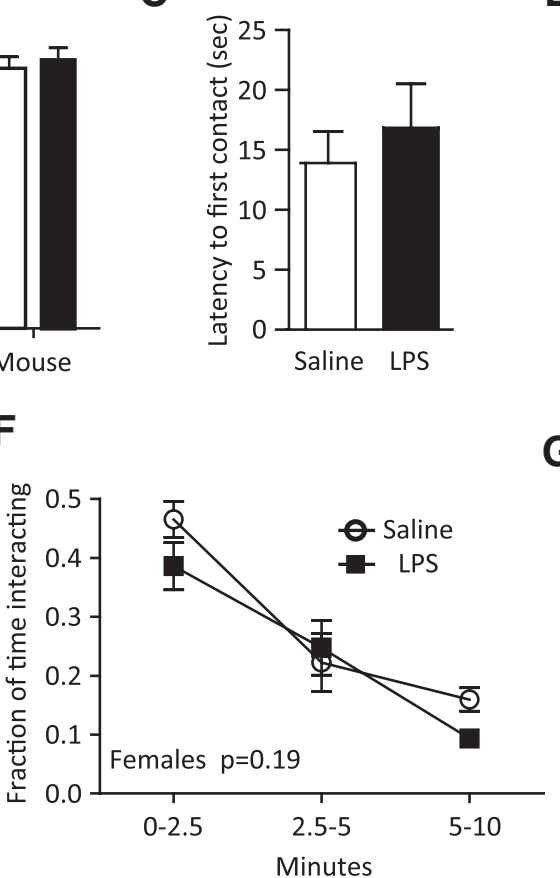

D

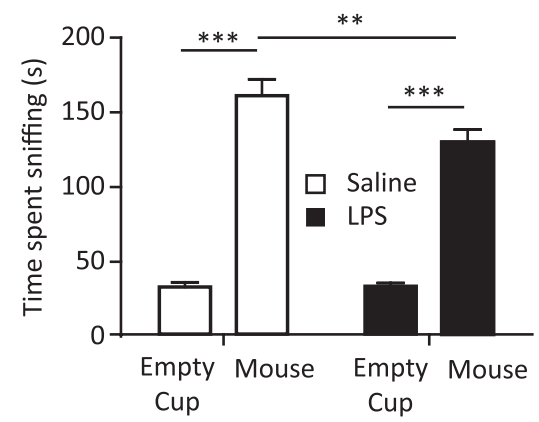

G

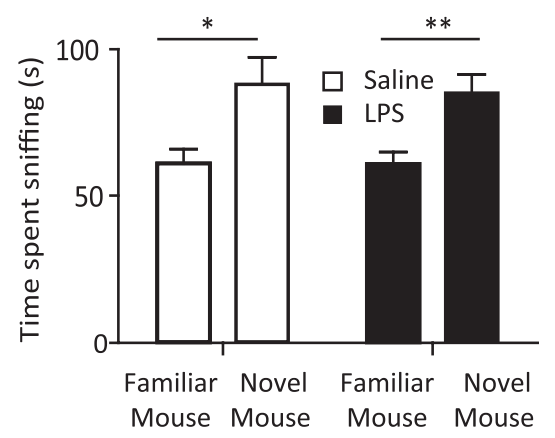

Figure 7. Impaired sociability but not social memory in LPS-exposed male offspring. Pups from E12.5-challenged pregnancies (saline vs $60 \mu \mathrm{g} / \mathrm{kg} \mathrm{LPS}$ ) were fostered to wild-type naive mothers and aged to 4 weeks. $\boldsymbol{A}$, Mice (20 saline, 11 male, 9 female from 4 pregnancies; 22 LPS, 14 male, 8 female from 4 pregnancies) were placed in a three-chambered testing apparatus with an empty center chamber and outer chambers each containing an inverted wire pencil cup. $\boldsymbol{B}$, The mice were habituated to the chamber with two empty pencil cups before social testing and the amount of time spent in each chamber was recorded. Data are expressed as the time spent in the chamber that will hold the mouse or the empty cup in the sociability phase of testing. There was a significant effect of position ( $p<0.001$ ) but not treatment by two-way ANOVA, but no significant bias toward future empty or mouse chambers by one-way ANOVA or Student's $t$ test. $C$, $\boldsymbol{D}$, To test sociability, a novel male mouse was placed in one of the cups. The test subject is placed in the middle chamber and its activity recorded for 10 min. The time to first contact was not different for the treatment groups (C). Each group spent increased time interacting with the novel mouse compared with the pencil cup ( $p<0.0001$ by paired $t$ test for both groups), but the LPS-challenged mice showed decreased time interacting with the mouse. Two-way ANOVA with repeated measures showed significant effects of the stimulus $(p<0.0001)$, treatment $(p=0.0379)$, and interaction $(p=$ 0.0341), and post hoc analysis showed a significant difference between saline at LPS-challenged mice in the time spent sniffing the mouse $\left(^{* *} p<0.01\right.$, Bonferroni $p 0$ st hoc test). $\boldsymbol{E}, \boldsymbol{F}, A$ breakdown of interaction in early, middle, and late phases of the 10 min interaction by gender revealed that the deficit in sociability is primarily in male mice in the $2.5-5$ min time period ( $p=0.005$ by two-way ANOVA, $\left.F_{(1,66)}=8.44\right)$, Bonferroni post hoc ${ }^{*} p<0.05$. G, To test social memory and preference for a novel mouse, the stimulus mouse was moved to the opposite chamber and a novel mouse was placed in the first chamber. The amount of time the test subject spent sniffing each mouse was recorded. Paired $t$ tests reveal that both groups spent significantly more time sniffing the novel mouse ( $p=0.025$ for saline and $p=0.0024$ for LPS). Two-way ANOVA with repeated measures shows a significant effect of the stimulus ( $p=0.0002$ ) but not treatment or interaction.

distance traveled against the chamber wall (region 1). Ambulatory velocity and episodes of ambulation were also not statistically different (data not shown). Mice were also observed for signs of repetitive or stereotypic behavior during the open field task and in their home cage. There were no overt signs of excessive grooming, jumping, circling, barbering, or other overtly abnormal activity.

\section{Discussion}

Systemic infections and other immune events in first or second trimester are associated with increased risk for neurodevelopmental disorders such as schizophrenia or autism (Brown et al., 2000; Beversdorf et al., 2005). Maternal inflammation also elicits changes in placental structure and/or placental gene expression (Hsiao and Patterson, 2011; Fatemi et al., 2012), as well as overt placental tissue damage when LPS is used as the immune stimulus (Carpentier et al., 2011). The gestational period of placental sensitivity corresponds with cortical neurogenesis, and we found that mild LPS-induced maternal illness at E12.5 is accompanied by a reduction in the abundance of cycling cells in the cortical VZ. We also found that a larger fraction of the dividing cells exits the cycle to become postmitotic following LPS challenge. Mitotic index remains depressed at E13.5 but rebounds to normal or slightly higher than normal at later times, a finding which replicates earlier studies and indicates that the proliferative perturbations are common to responses induced by LPS as well as the viral molecular pattern poly(I:C) (De Miranda et al., 2010; Soumiya et al., 2011).

We found that brain size is slightly reduced at early postnatal ages and cortical thickness is reduced in adults, but these reductions are proportional to similar reductions in body weight. This results in animals that are smaller overall but exhibit normal brain to body weight ratios. We also found evidence for a stereotypical disorganization of neuron abundance and location. Cortical development is tightly choreographed and the timing of the terminal cell division is important to determine the fate and permanent location of that neuron (Fame et al., 2011). A disturbance in proliferation or neuronal birthdates during cortical neurogenesis could lead to a variety of anatomical changes, not only in total cell number, but also in location or phenotype for selected neuronal subtypes that are being produced at the time of challenge. We found two significant alterations in the cortex involving (1) the laminar targeting of cells born on a given day and (2) neuronal subtype specification that controls cerebral versus subcerebral projection neuron identity (summarized in Fig. 11).

By examining the relative abundance and location of cells that were labeled with IdU at E12.5 or with CldU at E15.5, we found that LPS challenge during pregnancy had no significant effect on the total number of labeled cells present in the adult but did shift their laminar positions (Fig. 11A). Cells born at E12.5 were depleted from 
A

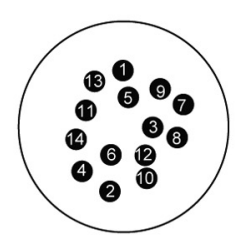

Daily Platform Positions

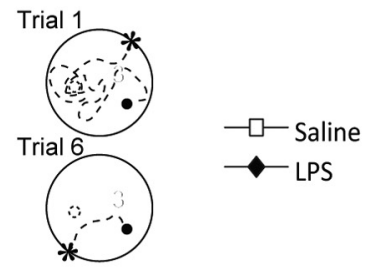

C

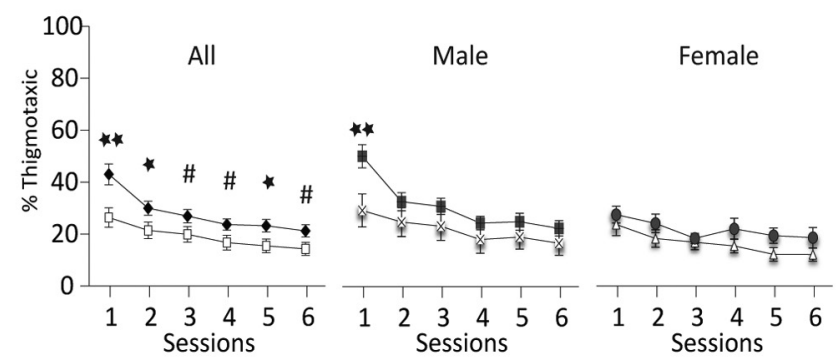

$\mathrm{E}$

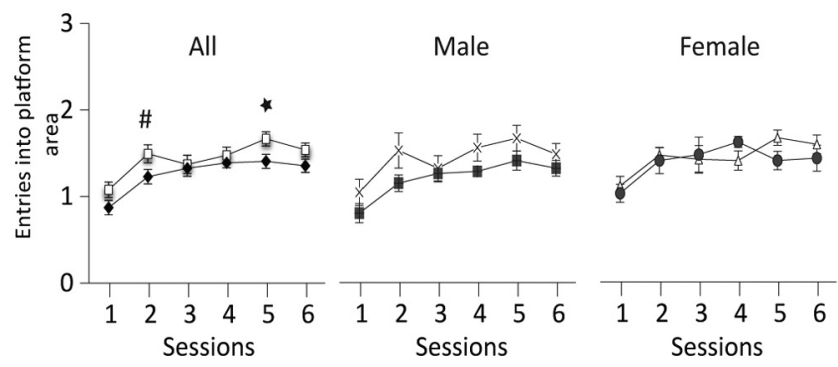

B
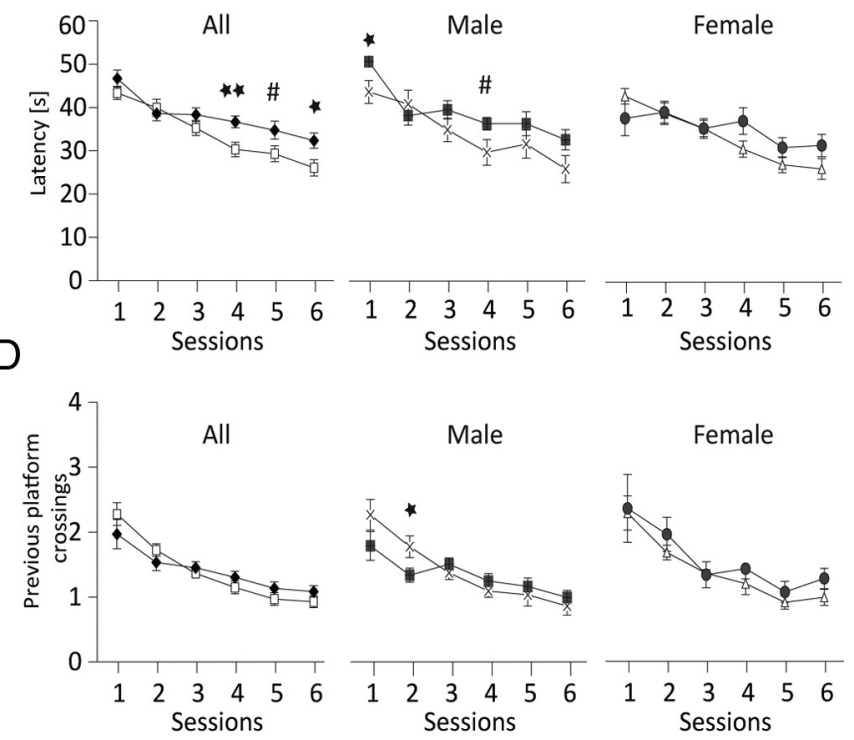

$\mathrm{F}$

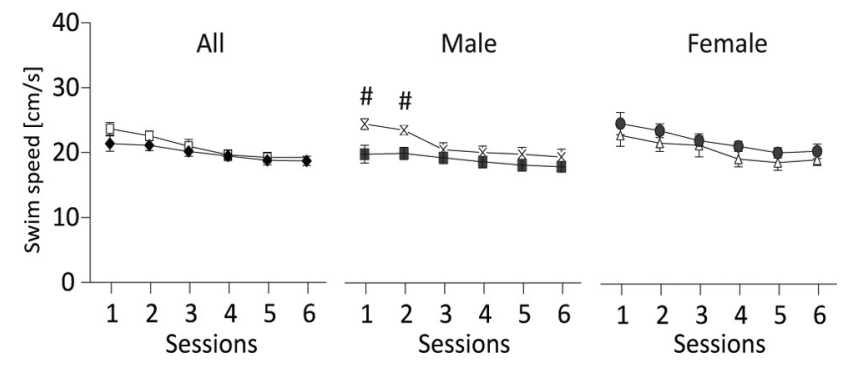

Figure 8. Defects in the DMP task in LPS-exposed mice. Pups from E12.5-challenged pregnancies (saline vs $60 \mu \mathrm{g} / \mathrm{kg}$ LPS) were fostered to wild-type naive mothers and aged to 5 weeks. $A$, Mice (21 saline, 10 male, 11 female from 5 pregnancies; 19 LPS, 13 male, 6 female from 6 pregnancies) were trained in the DMP task for $13 \mathrm{~d}$. On each day, animals are asked to find a new hidden platform position (Session 1) using visual cues in the testing room. Animals become increasingly proficient at finding the platform on subsequent trials. Data were averaged across days $2-13$ and represented as mean \pm SEM for male and female combined or separated by gender. $\boldsymbol{B}$, Latency to find the hidden platform. Offspring from LPS-challenged pregnancies never reach the same proficiency as control mice on the DMP task (latency averaged for each trial on days $2-13$ combined; $p=0.04$ for treatment effect by three-way ANOVA, $\left.F_{(1,38)}=4.2\right)$. C, Mice from LPS-challenged pregnancies spend more time in the outer annulus ( $p=0.02$ for treatment effect by three-way ANOVA, $\left.F_{(1,38)}=5.5\right)$. $D$, Preservative swimming to the previous day's platform position (number of times mice crossed the prior platform location; $p=0.9$ for treatment effect by three-way ANOVA, $\left.F_{(1,38)}=0.01\right)$. E, Entries into current platform area $(p=0.04$ for treatment effect by three-way ANOVA, $\left.F_{(1,38)}=4.3\right)$. $F$, Swim speed $\left(p=0.38\right.$ for treatment effect by three-way ANOVA, $\left.F_{(1,38)}=0.76\right) .{ }^{* *} p<0.01,{ }^{*} p<0.05$, and \#p $<0.07$ by Newman-Keuls post hoc test.
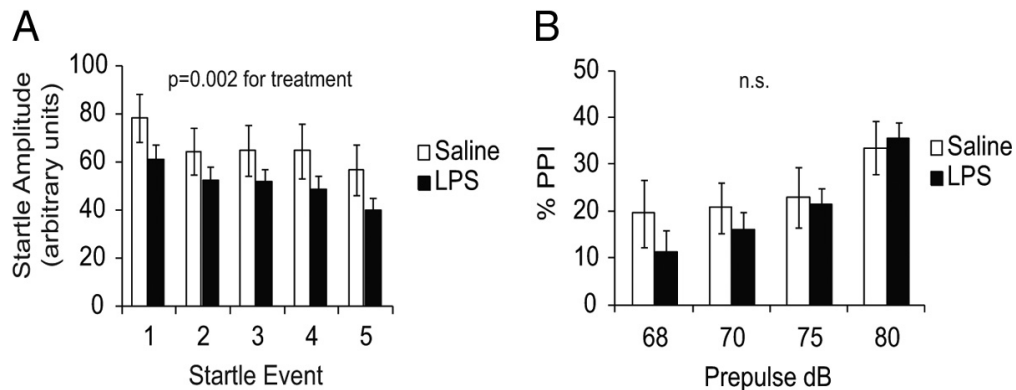

Figure 9. Acoustic startle and PPI. $A$, Mice were tested for startle response and habituation over five startle events using $110 \mathrm{~dB}$ white noise. Animals from LPS-challenged pregnancies showed reduced startle amplitude ( $p=0.002$ for treatment effect by two-way ANOVA, $n=19$ males, 16 females from 5 pregnancies for saline; 17 males, 22 females from 8 pregnancies for LPS). Mice displayed normal habituation to the startle tone. $\boldsymbol{B}$, PPI was measured over a range of $68-80 \mathrm{~dB}$ prepulses. Offspring from LPS-challenged pregnancies showed no significant change in the percentage PPI ( $p=0.29$ for treatment effect by two-way ANOVA).

inner layers and proportionally more abundant in the outer layers of the cortex. The alterations in laminar distribution are consistent with a delayed migration for cells produced at E12.5, which then may join later migrating cells to occupy the outer layers. Alternatively, cells produced during periods of placental insufficiency may migrate on time but may fail to stop migrating, either due to a failure to respond to reelin or a failure of CajalRetzius cells to provide a stop signal for migration. Cells born later in development at E15.5 show an opposite LPS effect on laminar positioning, with a higher than normal proportion of cells occupying deep layers. It is possible that unknown mechanisms cause later born cells to back-fill the E12.5 depleted deep layers or to cause these cells to stop migrating prematurely.

For both E12.5- and E15.5-born cells, the adult cortical layer I showed a reciprocal effect relative to the underlying cortical lamina, with a depletion of E12.5-labeled cells and over-representation of E15.5-labeled cells (Fig. $3 F, I$ ). The precise origins of layer I neurons remain somewhat controversial, but there is agreement that the predominant layer I neuron is the marginal zone-derived Cajal-Retzius cell, which 
has origins that are distinct from the cortical plate-derived projection neurons in layers II-VI (Hevner et al., 2003; Bielle et al., 2005; Soriano and Del Río, 2005; García-Moreno et al., 2007). In the adult, neither CR- nor reelin- positive cell abundance was altered in layer I. However, the observation that LPS challenge reduces the fraction of E12.5born cells present in adult cortical layer I and increases the fraction that is born later at E15.5 may suggest that Cajal-Retzius cell production may be transiently suppressed following the LPS challenge. Although speculative, this transient reduction could allow some E12.5-born cells to continue to migrate until a sufficient reelin signal is produced by later developing Cajal-Retzius cells. The divergence of layer I from the pattern of the other layers was also particularly interesting because cortical plate and marginal zone-derived cells have different origins and birthdates (Hevner et al., 2003; Bielle et al., 2005; Soriano and Del Río, 2005; García-Moreno et al., 2007).

An evaluation of projection neuron identity showed alterations in abundance and laminar distributions of Ctip2-, Satb2-, and Tbr1-expressing neurons but not later born Cux1-expressing neurons (Fig. 4). Ctip2, Satb2, and Tbr1 are transcriptional regulators that are required for the developmental specification of subcerebral (Ctip2) or cerebral projection neurons (Satb2, Tbr1; Alcamo et al., 2008; Leone et al., 2008; Bedogni et al., 2010; McKenna et al., 2011). The majority of Satb2- and Ctip2-expressing neurons are generated from $\sim$ E9.5 to E14.5. At birth, both neuronal populations are found predominantly in mid to inner cortical layers IV-VI, but the laminar range of Satb2-immunopositive neurons expands in the adult to occupy layers II-VI. Tbr1 marks a population of deep layer projection neurons (bins 8-10) that are born concurrent with Satb2 and Ctip2 neurons (Bedogni et al., 2010; McKenna et al., 2011). Tbr1 also marks a second population of layer II-III neurons in the adult that are born later in development and located in superficial cortical layers (Hevner et al., 2001; Molyneaux et al., 2007). Cux1 marks later born neurons that reside predominantly in superficial layers II-IV (laminar bins 2-5; Nieto et al., 2004) and we speculate that immune-related effects may be resolved before Cux1-positive neurons are generated.

Satb2-positive projection neurons were the most dramatically affected, with an approximate $40 \%$ reduction in cell density overall (Fig. $4 D-F$ ). The early born Tbr1-positive cells were also substantially depleted (Fig. 4G-I), and this was accompanied by an increase in Ctip2-positive neurons in the mid to outer layers of the cortex (Fig. 4A-C). The transcriptional network characterized by expression of Ctip 2 and Fezf2 is thought to compete with Satb2- and Tbr1-mediated transcriptional events to competitively specify subcerebral versus cerebral projection neuron subtypes, respectively. Satb2 specifies callosal projection neurons (Alcamo et al., 2008; Britanova et al., 2008; Chen et al., 2008), whereas Tbr1 is involved in specifying callosal and corticotha-
B

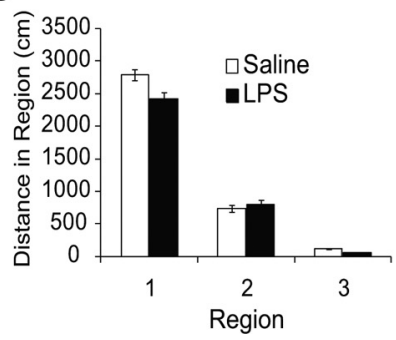

Figure 10. Open field exploration. $\boldsymbol{A}$, Mice were allowed to freely explore an open arena for $5 \mathrm{~min}$. Latency and distance traveled in each of three regions within the field was recorded. $\boldsymbol{B}$, Distance traveled within outer, middle, or inner regions is unchanged by prenatal exposure to LPS ( $p=0.61$ for treatment effect by three-way ANOVA with repeated measures, $F_{(1,45)}=0.27, n=47 \mathrm{from}$ 11 pregnancies). $C$, Mice show no significant differences in latency within each region ( $p=0.31$ for treatment effect by three-way

A

Illness-induced alterations in cortical patterning. $\boldsymbol{A}$, LPS-challenged offspring show significant alterations in the (n) laminar positioning, Satb2- and Tbr1-positive neuronal subtypes are selectively depleted (the functional consequences may include impairment in commissural and corticothalamic connectivity with an accompanying accentuation of connectivity to subcerebral targets.

lamic projection neurons (Bedogni et al., 2010; McKenna et al., 2011). The Ctip2/Fezf2 transcriptional cascade competes with Satb2 and Tbr1 to produce corticofugal projection neurons. It is known that genetic loss of Fezf 2 causes neurons to adopt Satb 2 or Tbr1 projection identities, whereas loss of Satb2 or Tbr1 causes reciprocal expansion of Ctip2/Fezf2 projection identity. Our results suggest that one of the consequences of an E12.5 challenge is an accentuation of Ctip2/Fezf2-related patterning with reciprocal inhibition of Satb1- and Tbr1-related patterning leading to a reduction in callosal and corticothalamic connectivity and simultaneous accentuation of subcerebral connections (Fig. 11B). The effects appear to be selective for cells being patterned during the immune event, since later born Tbr1-positive neurons located in the superficial layers of the cortex were not as significantly affected.

Effects on interneurons were less pronounced, and of the markers evaluated, only PV-positive interneurons were depleted from the deep layers of the cortex (Figs. 6F, 11B). Recent reports suggest Satb2- and Tbr1-expressing neurons promote the local accumulation of somatostatin and PVexpressing interneurons (Lodato et al., 2011). We observed here that the depletion of Satb2 and Tbr1 projection neurons is accompanied by a parallel depletion of PV interneurons 
(Fig. 6H), which is consistent with Satb2 and Tbr1 depletion causing a subsequent reduction in PV neuron recruitment. Together, these data indicate that the window of gestational vulnerability in the placenta may also have consequences for later developmental processes that are sensitive to the earlier activities of Ctip2/Fezf2, Satb2, and Tbr1.

The selective alteration of neuron subtypes along with subtle changes in interneuron abundance and distribution illustrate how illness might create functional changes in connectivity as well as in the balance of excitatory/inhibitory cell numbers within local cortical networks. Adult offspring show statistically significant alterations in socialization (Fig. 7), associative processing (Fig. 8), and acoustic startle (Fig. 9). Other functions, including locomotor activity, open field exploration, vision, olfaction, and PPI are statistically unaltered (Figs. 7, 9, 10). Given the extent of depletion of Satb2- and Tbr1expressing projection neurons in the adult, it is surprising that the functional effects are not more pronounced. However, it is important to remember that, unlike genetic models that result in the complete absence of a given neuronal subtype, animals in the present studies are genetically normal, and we speculate that natural compensatory mechanisms can accommodate significant environmental perturbations in fetal brain development.

The functional changes noted here do confirm and highlight a spectrum of behavioral alterations that have been reported following prenatal immune challenge in several model systems (Patterson, 2002; Meyer et al., 2007). These data also highlight three anatomical features that may be relevant to certain forms of ASD.

First, the effects on transcriptional cascades involving Ctip2/Fezf2, Satb2, and Tbr1 reduce the number of neurons that mediate callosal and thalamic connectivity and increase the abundance of neuronal subtypes mediating corticofugal connectivity (Fig. 11B). It has been suggested that ASD involves alterations in local and long distance connectivity (Geschwind and Levitt, 2007), and a large meta-analysis of imaging studies reveals a trend toward decreased callosal volumes in autistic patients (Frazier and Hardan, 2009), which may be analogous to the loss of commissural Satb2 neurons in the present mouse model. The reduced thickness of the CC in offspring from LPS-challenged pregnancies is consistent with a loss of callosal connectivity (Fig. 5B), and we also confirm that of the remaining callosal projections, fewer of these are from Satb2-positive neurons (Fig. 5F).

Second, we also observed selective depletion of PV-expressing interneurons in deep cortical layers (Fig. 6D). A speculative but interesting prediction is that these changes cause a local reduction of the PV/CR ratio and loss of inhibitory tone. An imbalance in excitatory versus inhibitory tone has also been implicated in some forms of ASD, and mouse genetic models for ASD implicate a potential common role for PV-expressing interneurons (Gogolla et al., 2009).

Finally, the behavioral anomalies, although mild, highlight changes in social interaction and associative processing that are thought to be relevant in mouse models of ASD (Crawley, 2007). It is particularly interesting to note that the behavioral phenotypes were more pronounced in male offspring, which correlates with the male predominance of ASD (Baron-Cohen et al., 2011). The reason why female mice are less affected remains unknown. The anatomical studies show that female mice have pronounced loss of Satb2 neurons (Fig. 4O), suggesting that behavioral differences are not entirely due to the absence of anatomical alterations in female animals. At present, the detailed anatomical studies have not been performed on a sufficient number of male and female animals to determine whether the anatomical changes are more pronounced in males, and future studies may determine whether female resilience is due to the absence of anatomical change or due to other compensatory mechanisms that attenuate behavioral consequences in female animals.

From our studies in mice, we concluded that mild illness alone is unlikely to cause frank developmental disability. Several of the anatomical measures and the behavioral phenotypes observed were mild but fairly consistent. Although markers for some projection neuron subtypes, such as Satb2, are substantially perturbed, the subtle behavioral deficits observed in our model reflect the likelihood that compensatory mechanisms can absorb significant alterations in fetal brain development. Future work could determine whether mild alterations in specific neuronal subtypes cause similar behavioral phenotypes and whether the severities of anatomical and behavioral phenotypes are related at various ages. Given the mild behavioral phenotypes in the present study, it seems more plausible that the clinical associations between gestational illness and developmental disorder in humans are due to genetic predisposition(s) that are exacerbated by illness to generate features of autism or schizophrenia. Such synergies may include maternal genetics that influence mother's immune response, genetics that alter placenta vulnerability, and/or fetal genetics that add to or amplify the effects of maternal immune event on the developing fetal brain.

\section{References}

Alcamo EA, Chirivella L, Dautzenberg M, Dobreva G, Fariñas I, Grosschedl R, McConnell SK (2008) Satb2 regulates callosal projection neuron identity in the developing cerebral cortex. Neuron 57:364-377. CrossRef Medline

Baron-Cohen S, Lombardo MV, Auyeung B, Ashwin E, Chakrabarti B, Knickmeyer R (2011) Why are autism spectrum conditions more prevalent in males? PLoS Biol 9:e1001081. CrossRef Medline

Bedogni F, Hodge RD, Elsen GE, Nelson BR, Daza RA, Beyer RP, Bammler TK, Rubenstein JL, Hevner RF (2010) Tbrl regulates regional and laminar identity of postmitotic neurons in developing neocortex. Proc Nat Acad Sci U S A 107:13129-13134. CrossRef Medline

Beversdorf DQ, Manning SE, Hillier A, Anderson SL, Nordgren RE, Walters SE, Nagaraja HN, Cooley WC, Gaelic SE, Bauman ML (2005) Timing of prenatal stressors and autism. J Autism Dev Disord 35:471-478. CrossRef Medline

Bielle F, Griveau A, Narboux-Nême N, Vigneau S, Sigrist M, Arber S, Wassef M, Pierani A (2005) Multiple origins of Cajal-Retzius cells at the borders of the developing pallium. Nat Neurosci 8:1002-1012. CrossRef Medline

Bozdagi O, Sakurai T, Papapetrou D, Wang X, Dickstein DL, Takahashi N, Kajiwara Y, Yang M, Katz AM, Scattoni ML, Harris MJ, Saxena R, Silverman JL, Crawley JN, Zhou Q, Hof PR, Buxbaum JD (2010) Haploinsufficiency of the autism-associated Shank3 gene leads to deficits in synaptic function, social interaction, and social communication. Mol Autism 1:15. CrossRef Medline

Britanova O, de Juan Romero C, Cheung A, Kwan KY, Schwark M, Gyorgy A, Vogel T, Akopov S, Mitkovski M, Agoston D, Sestan N, Molnár Z, Tarabykin V (2008) Satb2 is a postmitotic determinant for upper-layer neuron specification in the neocortex. Neuron 57:378-392. CrossRef Medline

Brown AS, Schaefer CA, Wyatt RJ, Goetz R, Begg MD, Gorman JM, Susser ES (2000) Maternal exposure to respiratory infections and adult schizophrenia spectrum disorders: a prospective birth cohort study. Schizophr Bull 26:287-295. CrossRef Medline

Carpentier PA, Dingman AL, Palmer TD (2011) Placental TNF-alpha signaling in illness-induced complications of pregnancy. Am J Pathol 178: 2802-2810. CrossRef Medline

Chen B, Wang SS, Hattox AM, Rayburn H, Nelson SB, McConnell SK (2008) The Fezf2-Ctip2 genetic pathway regulates the fate choice of subcortical projection neurons in the developing cerebral cortex. Proc Natl Acad Sci U S A 105:11382-11387. CrossRef Medline

Crawley JN (2007) Mouse behavioral assays relevant to the symptoms of autism. Brain Pathol 17:448-459. CrossRef Medline 
Croen LA, Grether JK, Yoshida CK, Odouli R, Van de Water J (2005) Maternal autoimmune diseases, asthma and allergies, and childhood autism spectrum disorders: a case-control study. Arch Pediatr Adolesc Med 159: 151-157. CrossRef Medline

De Miranda J, Yaddanapudi K, Hornig M, Villar G, Serge R, Lipkin WI (2010) Induction of Toll-like receptor 3-mediated immunity during gestation inhibits cortical neurogenesis and causes behavioral disturbances. MBio 1.

Fame RM, MacDonald JL, Macklis JD (2011) Development, specification, and diversity of callosal projection neurons. Trends Neurosci 34:41-50. CrossRef Medline

Fatemi SH, Folsom TD, Rooney RJ, Mori S, Kornfield TE, Reutiman TJ, Kneeland RE, Liesch SB, Hua K, Hsu J, Patel DH (2012) The viral theory of schizophrenia revisited: abnormal placental gene expression and structural changes with lack of evidence for $\mathrm{H} 1 \mathrm{~N} 1$ viral presence in placentae of infected mice or brains of exposed offspring. Neuropharmacology 62: 1290-1298. Medline

Frazier TW, Hardan AY (2009) A meta-analysis of the corpus callosum in autism. Biol Psychiatry 66:935-941. CrossRef Medline

García-Moreno F, López-Mascaraque L, De Carlos JA (2007) Origins and migratory routes of murine Cajal-Retzius cells. J Comp Neurol 500:419432. CrossRef Medline

Geschwind DH, Levitt P (2007) Autism spectrum disorders: developmental disconnection syndromes. Curr Opin Neurobiol 17:103-111. CrossRef Medline

Gogolla N, Leblanc JJ, Quast KB, Südhof TC, Fagiolini M, Hensch TK (2009) Common circuit defect of excitatory-inhibitory balance in mouse models of autism. J Neurodev Disord 1:172-181. CrossRef Medline

Golan HM, Lev V, Hallak M, Sorokin Y, Huleihel M (2005) Specific neurodevelopmental damage in mice offspring following maternal inflammation during pregnancy. Neuropharmacology 48:903-917. CrossRef Medline

Haditsch U, Leone DP, Farinelli M, Chrostek-Grashoff A, Brakebusch C, Mansuy IM, McConnell SK, Palmer TD (2009) A central role for the small GTPase Racl in hippocampal plasticity and spatial learning and memory. Mol Cell Neurosci 41:409-419. CrossRef Medline

Herr KJ, Herr DR, Lee CW, Noguchi K, Chun J (2011) Stereotyped fetal brain disorganization is induced by hypoxia and requires lysophosphatidic acid receptor 1 (LPA1) signaling. Proc Natl Acad Sci U S A 108: 15444-15449. CrossRef Medline

Hevner RF, Shi L, Justice N, Hsueh Y, Sheng M, Smiga S, Bulfone A, Goffinet AM, Campagnoni AT, Rubenstein JL (2001) Tbrl regulates differentiation of the preplate and layer 6. Neuron 29:353-366. CrossRef Medline

Hevner RF, Neogi T, Englund C, Daza RA, Fink A (2003) Cajal-Retzius cells in the mouse: transcription factors, neurotransmitters, and birthdays suggest a pallial origin. Brain Res Dev Brain Res 141:39-53. CrossRef Medline

Hsiao EY, Patterson PH (2011) Activation of the maternal immune system induces endocrine changes in the placenta via IL-6. Brain Behav Immun 25:604-615. CrossRef Medline

Knox K, Baker JC (2008) Genomic evolution of the placenta using cooption and duplication and divergence. Genome Res 18:695-705. CrossRef Medline

Knox KS, Baker JC (2007) Genome-wide expression profiling of placentas in the p57Kip2 model of pre-eclampsia. Mol Hum Reprod 13:251-263. CrossRef Medline

Leone DP, Srinivasan K, Chen B, Alcamo E, McConnell SK (2008) The de- termination of projection neuron identity in the developing cerebral cortex. Curr Opin Neurobiol 18:28-35. CrossRef Medline

Lodato S, Rouaux C, Quast KB, Jantrachotechatchawan C, Studer M, Hensch TK, Arlotta P (2011) Excitatory projection neuron subtypes control the distribution of local inhibitory interneurons in the cerebral cortex. Neuron 69:763-779. CrossRef Medline

McKenna WL, Betancourt J, Larkin KA, Abrams B, Guo C, Rubenstein JL, Chen B (2011) Tbr1 and Fezf2 regulate alternate corticofugal neuronal identities during neocortical development. J Neurosci 31:549-564. CrossRef Medline

Meyer U, Nyffeler M, Engler A, Urwyler A, Schedlowski M, Knuesel I, Yee BK, Feldon J (2006) The time of prenatal immune challenge determines the specificity of inflammation-mediated brain and behavioral pathology. J Neurosci 26:4752-4762. CrossRef Medline

Meyer U, Yee BK, Feldon J (2007) The neurodevelopmental impact of prenatal infections at different times of pregnancy: the earlier the worse? Neuroscientist 13:241-256. CrossRef Medline

Meyer U, Nyffeler M, Yee BK, Knuesel I, Feldon J (2008) Adult brain and behavioral pathological markers of prenatal immune challenge during early/middle and late fetal development in mice. Brain Behav Immun 22:469-486. CrossRef Medline

Molyneaux BJ, Arlotta P, Menezes JR, Macklis JD (2007) Neuronal subtype specification in the cerebral cortex. Nat Rev Neurosci 8:427-437. CrossRef Medline

Nieto M, Monuki ES, Tang H, Imitola J, Haubst N, Khoury SJ, Cunningham J, Gotz M, Walsh CA (2004) Expression of Cux-1 and Cux-2 in the subventricular zone and upper layers II-IV of the cerebral cortex. J Comp Neurol 479:168-180. CrossRef Medline

Patterson PH (2002) Maternal infection: window on neuroimmune interactions in fetal brain development and mental illness. Curr Opin Neurobiol 12:115-118. CrossRef Medline

Shi L, Fatemi SH, Sidwell RW, Patterson PH (2003) Maternal influenza infection causes marked behavioral and pharmacological changes in the offspring. J Neurosci 23:297-302. Medline

Silverman JL, Babineau BA, Oliver CF, Karras MN, Crawley JN (2013) Influence of stimulant-induced hyperactivity on social approach in the BTBR mouse model of autism. Neuropharmacology 68:210-222. CrossRef Medline

Soriano E, Del Río JA (2005) The cells of Cajal-Retzius: still a mystery one century after. Neuron 46:389-394. CrossRef Medline

Soumiya H, Fukumitsu H, Furukawa S (2011) Prenatal immune challenge compromises the normal course of neurogenesis during development of the mouse cerebral cortex. J Neurosci Res 89:1575-1585. CrossRef Medline

Steele RJ, Morris RG (1999) Delay-dependent impairment of a match-toplace task with chronic and intrahippocampal infusion of the NMDAantagonist D-AP5. Hippocampus 9:118-136. CrossRef Medline

Treit D, Fundytus M (1988) Thigmotaxis as a test for anxiolytic activity in rats. Pharmacol Biochem Behav 31:959-962. CrossRef Medline

Yang M, Crawley JN (2009) Simple behavioral assessment of mouse olfaction. Curr Protoc Neurosci Chapter 8:Unit 8.24. CrossRef Medline

Zuckerman L, Rehavi M, Nachman R, Weiner I (2003) Immune activation during pregnancy in rats leads to a postpubertal emergence of disrupted latent inhibition, dopaminergic hyperfunction, and altered limbic morphology in the offspring: a novel neurodevelopmental model of schizophrenia. Neuropsychopharmacology 28:1778-1789. CrossRef Medline 